OPEN ACCESS

Edited by: Massimo Reverberi,

Sapienza University of Rome, Italy

Reviewed by:

Giovanni Beccari,

University of Perugia, Italy

Ralph Hückelhoven,

Technical University of Munich,

Germany

${ }^{*}$ Correspondence:

Ida Karlsson

ida.karlsson@s/u.se

Specialty section:

This article was submitted to Microbe and Virus Interactions with

Plants,

a section of the journa

Frontiers in Microbiology

Received: 11 November 2020

Accepted: 08 February 2021

Published: 01 March 2021

Citation:

Karlsson I, Persson P and Friberg H (2021) Fusarium Head

Blight From a Microbiome

Perspective.

Front. Microbiol. 12:628373. doi: 10.3389/fmicb.2021.628373

\section{Fusarium Head Blight From a Microbiome Perspective}

\author{
Ida Karlsson ${ }^{*}$, Paula Persson ${ }^{1}$ and Hanna Friberg ${ }^{2}$ \\ ${ }^{1}$ Department of Crop Production Ecology, Swedish University of Agricultural Sciences, Uppsala, Sweden, ${ }^{2}$ Department \\ of Forest Mycology and Plant Pathology, Swedish University of Agricultural Sciences, Uppsala, Sweden
}

The fungal genus Fusarium causes several diseases in cereals, including Fusarium head blight (FHB). A number of Fusarium species are involved in disease development and mycotoxin contamination. Lately, the importance of interactions between plant pathogens and the plant microbiome has been increasingly recognized. In this review, we address the significance of the cereal microbiome for the development of Fusarium-related diseases. Fusarium fungi may interact with the host microbiome at multiple stages during their life cycles and in different plant organs including roots, stems, leaves, heads, and crop residues. There are interactions between Fusarium and other fungi and bacteria as well as among Fusarium species. Recent studies have provided a map of the cereal microbiome and revealed how different biotic and abiotic factors drive microbiome assembly. This review synthesizes the current understanding of the cereal microbiome and the implications for Fusarium infection, FHB development, disease control, and mycotoxin contamination. Although annual and regional variations in predominant species are significant, much research has focused on Fusarium graminearum. Surveying the total Fusarium community in environmental samples is now facilitated with novel metabarcoding methods. Further, infection with multiple Fusarium species has been shown to affect disease severity and mycotoxin contamination. A better mechanistic understanding of such multiple infections is necessary to be able to predict the outcome in terms of disease development and mycotoxin production. The knowledge on the composition of the cereal microbiome under different environmental and agricultural conditions is growing. Future studies are needed to clearly link microbiome structure to Fusarium suppression in order to develop novel disease management strategies for example based on conservation biological control approaches.

Keywords: Fusarium head blight (FHB), scab, Fusarium crown rot (FCR), cereals, pathogen-pathogen interactions, pathogen-microbe interactions

\section{INTRODUCTION}

Fusarium head blight (FHB) is one of the most important cereal diseases worldwide. The disease results in reduced yields and mycotoxin contamination of the grain. Several different Fusarium species are associated with FHB. The predominant species varies with region and climate. Globally, Fusarium graminearum is considered the predominant causal species of FHB (Starkey et al., 2007; Summerell et al., 2010). In Europe, F. graminearum, Fusarium culmorum, Fusarium poae, 
and Fusarium avenaceum are considered to be most common (Xu et al., 2008; Becher et al., 2013). Often, several Fusarium species are present simultaneously, and may interact with each other, influencing disease development and mycotoxin production. In this review, we use the term "FHB species complex" to refer to the Fusarium species associated to FHB and mycotoxin contamination in cereals.

Fusarium fungi can in addition to FHB cause other diseases in cereals during their life cycle including seedling blight, root rot and Fusarium crown rot (FCR; Parry et al., 1995; Kazan et al., 2012). Many Fusarium species are capable of producing mycotoxins, in some cases also in absence of severe disease symptoms. The mycotoxins of greatest concern include the trichothecenes deoxynivalenol (DON), nivalenol, and HT2/T2, and the oestrogenic mycotoxin zearalenone (ZEA; Bottalico and Perrone, 2002). F. graminearum and F. culmorum are important producers of DON, ZEA, and nivalenol, the latter may also be produced by F. poae (Bottalico and Perrone, 2002). Fusarium langsethiae and Fusarium sporotrichioides are producers of the HT2 and T2 toxins (Thrane et al., 2004). Novel analytical methods has made it possible to analyze many mycotoxins simultaneously. This has drawn the attention to so called "emerging" Fusarium toxins, where knowledge on toxicity is limited (Fraeyman et al., 2017). Examples include enniatins and moniliformin which may be produced by $F$. avenaceum (Morrison et al., 2002). For a recent overview of mycotoxinproducing Fusarium species see Venkatesh and Keller (2019). To protect consumer health, legal limits have been set in many countries for maximum mycotoxin content in unprocessed grain and foodstuffs. In Europe, DON, ZEA, and fumonisins are regulated (European Commission, 2006). The legislation will likely cover more mycotoxins in the future such as HT2/T2 (Knutsen et al., 2017). Another topic of discussion is the existence of conjugated toxin forms, formed when metabolized by the plant, sometimes called "masked mycotoxins" (Zhang et al., 2020). Fusarium mycotoxins are a concern for human and animal health and the economic consequences may be severe when contaminated grain cannot be used for food or feed.

Certain risk factors for FHB are well-known. Weather conditions at flowering is one of the most important factors for infection along with certain cropping practices such as reduced tillage and maize as a preceding crop to cereals (Dill-Macky and Jones, 2000; Beyer et al., 2006; Edwards and Jennings, 2018). Inconsistent results have been obtained for nitrogen fertilization which has been linked both to increased and decreased FHB symptoms and mycotoxin accumulation (Lemmens et al., 2004; Heier et al., 2005; Hofer et al., 2016; Zetzsche et al., 2020). Effective chemical control is often difficult to achieve as it is dependent on optimal timing of the fungicide application (Wegulo et al., 2015). However, interactions with naturally occurring microorganisms is less well-understood and is the focus of this review.

Plants are increasingly seen as holobionts where plantassociated microbiota play an important role for plant fitness (Vandenkoornhuyse et al., 2015). Plants harbor complex microbial communities both below- and aboveground. Advances in this research area are deeply influenced by the development of metabarcoding approaches and omics to study phytobiomes (Rastogi et al., 2013). In plant pathology, these tools have opened up new possibilities to understand for instance, disease suppressive soils or to improve biocontrol applications (Massart et al., 2015; Schlatter et al., 2017). The existence of specific beneficial microbial strains has been known for decades. These may have both direct and indirect effects on the plant including induced systemic resistance, production of secondary metabolites, hormones or through nutrient effects (van Loon, 2007). Plant-associated microorganisms may also facilitate the infection by plant pathogens (Dewey et al., 1999). Recently, evidence is gathering that it is not solely the individual strains that are important for plant health but also the microbial community both aboveground (Ritpitakphong et al., 2016; Zahn and Amend, 2017) and belowground (Hol et al., 2015; Hu et al., 2016).

In this review, we highlight FHB and associated diseases from a microbiome perspective. In the first part, starting with a review of the FHB disease cycle, a holistic view of Fusarium spp. in cereals is taken. Novel methods to survey the Fusarium community composition are described. Next, interactions between different Fusarium species and the implications for FHB disease development and mycotoxin contamination are reviewed. In the second part, we synthesize recent findings concerning the cereal microbiome in different plant organs. Finally, the importance of the microbiome for FHB and the potential for prevention or control of the disease and mycotoxin accumulation is discussed.

\section{FHB DISEASE CYCLE}

Fusarium species differ in their biology, for instance the types of spores they produce. These characteristics will influence how they are spread within agroecosystems. Fusarium species produce asexual conidia and several species, for example F. graminearum and $F$. avenaceum, also have sexually produced ascospores. The sexual stages were previously described by their teleomorph names in the genus Gibberella (Geiser et al., 2013). Some species also produce chlamydospores with thicker cell walls with the possibility to survive in the soil, such as F. culmorum and F. graminearum (Leslie and Summerell, 2006). Spore dissemination is a critical step for the fungus to colonize new plant parts. The sexual ascospores are known to be released by active mechanisms of the perithecia while conidia, the asexual spores, are dependent on wind or rain for liberation (Trail et al., 2005). Macroconidia are reported to be splash-dispersed short distances within the canopy while ascospores can be transported longer distances by wind (Keller et al., 2014). The spore type might also be of importance for disease development. For instance, ascospores of F. graminearum were shown to be less effective in causing FHB and FCR than conidia, although the difference in FHB severity between the two spore types was small (Mitter et al., 2006).

There has been a long debate on whether local or airtransported spores are the main inoculum source of FHB epidemics caused by F. graminearum (Keller et al., 2014). In aerial samples $60 \mathrm{~m}$ above ground level, twice as many ascospores 
compared to macroconidia were reported by MaldonadoRamirez et al. (2005). They showed that viable F. graminearum spores were abundant in the air every hour of the day and night indicating that that the source of these spores was likely several kilometers away. Transport of F. graminearum in the atmosphere may be responsible for initiating disease many kilometers from the inoculum source. Thus, in addition to the presence of the pathogen at the field level, atmospheric inoculum needs to be taken into account when evaluating the risk of FHB.

Contaminated crop residues are an important Fusarium inoculum source as they allow for saprotrophic survival of the pathogen (Leplat et al., 2012). Maize is the preceding crop associated with highest risk of FHB since it is a good host for Fusarium spp. and produce large amounts of residues (DillMacky and Jones, 2000; Tillmann et al., 2017). Several of the species that are important for FHB can survive on crop residues. This applies for example to F. graminearum, F. culmorum, $F$. avenaceum, F. poae, and F. sporotrichioides. For F. langsethiae, the role of crop residues for pathogen survival is less clear, although studies have shown a correlation between residue retention in the field and increased disease (Hofgaard et al., 2016b). Due to the important role of crop residues, a wellplanned cropping sequence and tillage strategy are important parts of crop protection strategies against FHB. When soils are plowed and residues are buried in the soil, this means that the residues are no longer in close contact with the crop canopy. It also means that the residues are exposed to soil organisms in an environment that stimulates microbial growth and microbial decomposition of the residues.

Spore production varies between Fusarium species and over the growing season. By analyzing Fusarium DNA from spore traps in Norway, Hofgaard et al. (2016b), observed that $F$. avenaceum had a less marked peak of spore dispersal than F. graminearum, but had a relatively stable dispersal of spores from shortly before heading until harvest time. Hellin et al. (2018) showed from studies in Belgium that inoculum of F. graminearum was present not only during the flowering period but also throughout the year with large amounts detected late in the season. This is also confirmed by Swedish studies showing that F. graminearum perithecia and ascospores are produced during the entire growing season on artificially inoculated maize and wheat straw in the field (Persson and Bötker, 2014). This indicates that aerial Fusarium spores are present and could potentially infect cereal crops during the entire growing season.

It is well known that the most important window for head infection by Fusarium species causing FHB is during cereal anthesis (Hooker et al., 2002) whereas the importance of aerial spore loads after anthesis is unclear. Siou et al. (2014) showed that anthesis is the critical window for FHB infection of wheat but also that later infections may lead to a significant development of the fungus, along with the accumulation of toxins in the kernels, although with limited symptom development. The authors claim that late infections may lead to significant toxin levels and might also have consequences for the seed production with viable but Fusarium-contaminated seeds. It has also been shown in barley and oats that infection can occur after anthesis (Yoshida et al., 2007; Tekle et al., 2012). Interestingly, the effect of infection time varies with different Fusarium species (Beccari et al., 2019).

The inoculum for FHB may thus come both from sources within the field or from aerial spore depositions originating from outside the field, and occur at different growth stages. This means that the potential for interactions between Fusarium species and the plant microbiome will vary over time and with plant organ (Figure 1).

\section{INTERACTIONS WITHIN THE FHB SPECIES COMPLEX}

\section{FHB Species Complex}

The genus Fusarium is diverse, containing species with various ecological characteristics. Several species are commonly found associated with plant tissue, with influence ranging from severely pathogenic to highly beneficial as biological control agents. Studies on the abundance and distribution of species associated with cereal crops have mainly focused on pathogens causing either FHB or FCR or on species that cause problems due to their mycotoxin production. There is a considerable spatiotemporal variation in the presence and relative abundance of species in association with FHB on a specific host plant. This variation is determined by climatic factors, especially temperature and moisture (Vogelgsang et al., 2017), crop species (Kosiak et al., 2003; Schöneberg et al., 2016, 2018) plant part (Tillmann et al., 2017), region and year (Yli-Mattila, 2010; Sundheim et al., 2013; Hofgaard et al., 2016b; Vogelgsang et al., 2017), and by cultural practices favoring certain species (Schöneberg et al., 2018). There may also be geographical restrictions to species distributions (Yli-Mattila, 2010).

A broad range of Fusarium species have been associated with FHB in cereals. In addition, the pathogens Microdochium nivale and Microdochium majus are commonly included in the concept of FHB as these species can cause head blight symptoms (Xu et al., 2005; Oerke et al., 2010; Nielsen et al., 2011). There is a large variability in the importance of the different species for FHB disease severity and mycotoxin contamination. Some species cause both severe disease symptoms and mycotoxin contamination of grains, for instance F. graminearum and F. culmorum. In contrast, species within the genus Microdochium are not known to produce any mycotoxins (Brennan et al., 2005; Gavrilova et al., 2020). Other species, such as F. langsethiae can produce potent mycotoxins while causing limited symptoms (Imathiu et al., 2013). Since it is not easy to make a clear delimitation of the FHB species complex based on pathogenicity or toxigenicity, we here include all Fusarium species associated with cereals together with $M$. nivale and $M$. majus in the concept.

The number of Fusarium species associated with cereal grain has in the literature been estimated to around 15 species, including $M$. nivale and M. majus (Bottalico and Perrone, 2002; Liddell, 2003). We reviewed the recent literature to identify the range of Fusarium species occurring in cereals in Europe, identifying 17 species of which many were only reported sporadically and/or in low abundance (Table 1). A literature review identified that F. graminearum, F. culmorum, 


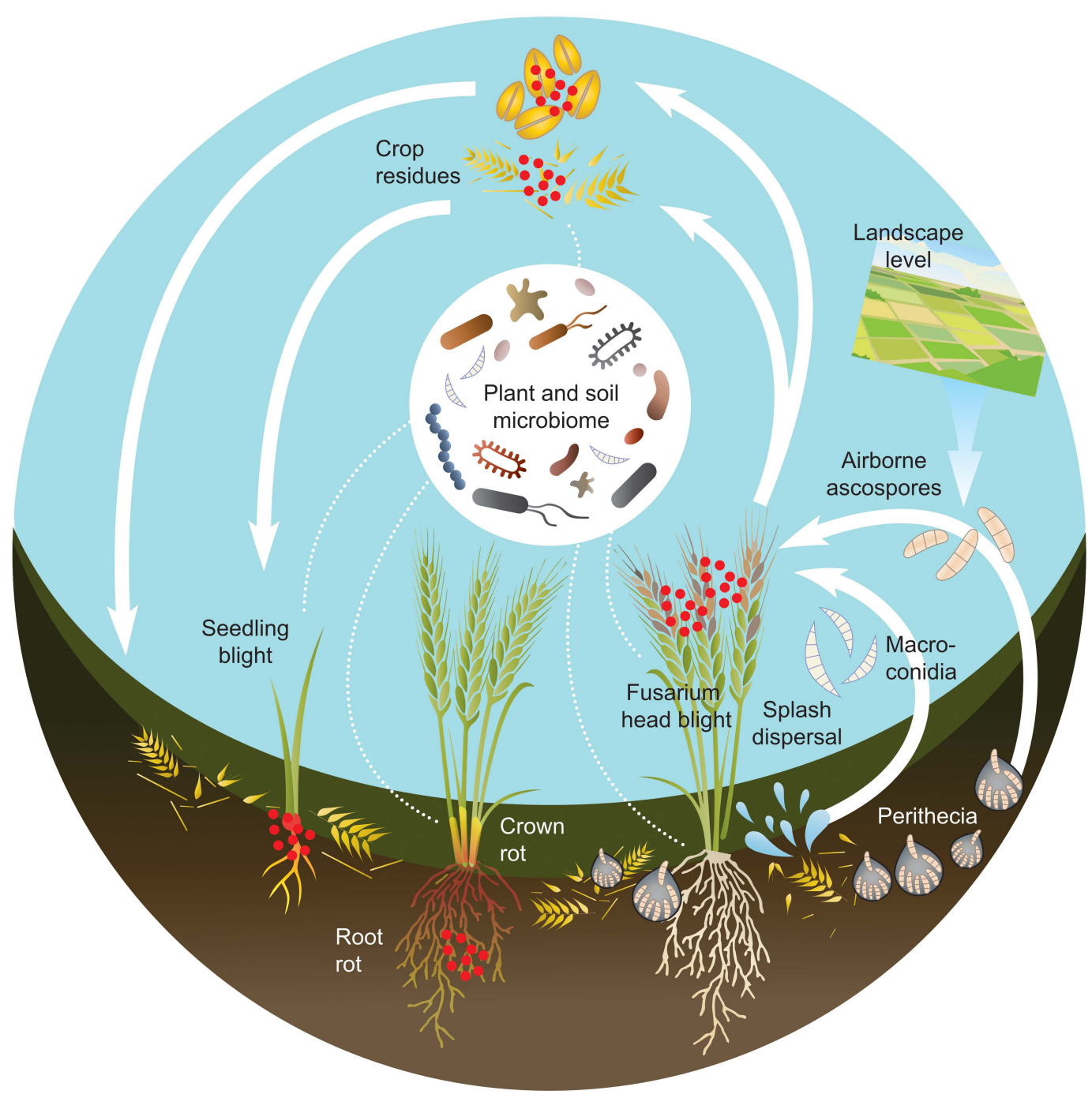

FIGURE 1 | Schematic figure over the disease cycle and microbiome interactions of Fusarium-related diseases in cereals, based on the life cycle of $F$. graminearum. The red dots represent Fusarium inoculum. Fusarium fungi can cause several diseases during the development of cereal crops including: seedling blight, Fusarium root rot, Fusarium crown rot and Fusarium head blight. Fusarium inoculum can originate both from the field itself, if present in crop residues or soil. It can also be introduced by infected seed or by deposition of spores from other areas. Other microorganisms are present both in the soil and on the plant. The microbiome structure varies depending on both plant organ, plant developmental stage, environmental and agricultural factors. Fusarium species are in constant contact with various microbiomes throughout the entire disease cycle.

$F$. avenaceum, and $F$. poae had the highest incidence in Europe (Becher et al., 2013). The species with the highest incidence may differ from those with the highest abundance. For instance, $F$. avenaceum had the highest incidence, while F. graminearum had the highest relative abundance in wheat samples in Sweden (Karlsson et al., 2017a).

Previously, F. culmorum was considered to be more prevalent in Northern Europe and F. graminearum to be more prevalent in Southern Europe (Bottalico and Perrone, 2002). A shift in the predominant species from $F$. culmorum to $F$. graminearum has been described in Northern Europe in recent decades (Jennings et al., 2004; Waalwijk et al., 2004; Nielsen et al., 2011; Bilska et al., 2018; Hofer et al., 2019). It has been suggested that the shift towards F. graminearum could be due to increased practice of reduced tillage and maize cultivation, or to climatic factors (Nielsen et al., 2011; Parikka et al., 2012). In Italy, a shift in predominant species from $F$. graminearum to $F$. poae has been observed in recent years (Beccari et al., 2017). Similar observations have been made in Canada, and it is speculated that $F$. poae is favored by dry conditions compared to F. graminearum (Valverde-Bogantes et al., 2019).

A shift in the population structure of $F$. graminearum from $15 \mathrm{ADON}$ chemotypes towards more toxigenic 3ADON chemotypes has been observed in North America (Ward et al., 2008), and recently a third F. graminearum chemotype - NX2 - was identified producing a novel type A trichothecene (Kelly and Ward, 2018). In Europe, the 15ADON chemotype dominates in Southern Europe and the $3 \mathrm{ADON}$ in Northern 
TABLE 1 | Diversity ${ }^{\star}$ of Fusarium and Microdochium species reported from cereal grain in Europe.

\begin{tabular}{lc}
\hline Species & References \\
\hline F. acuminatum & 7,8 \\
F. avenaceum & $1,2,3,4,5,6,7,8$ \\
F. chlamydosporum & 4 \\
F. crookwellense (F. cerealis) & $2,4,5,6$ \\
F. culmorum & $1,2,3,4,5,6,7,8$ \\
F. dimerum & 6 \\
F. equiseti & $2,4,5,6,8$ \\
F. graminearum & $1,2,3,5,6,7,8$ \\
F. langsethiae & $3,5,6,7,8$ \\
F. lateritium & 7 \\
F. proliferatum & 4 \\
F. poae & $1,2,3,4,5,6,7,8$ \\
F. sambucinum & 4 \\
F. semitectum & $4,3,4,5,6,7,8$ \\
F. sporotrichioides & 4 \\
F. subglutinans & $2,3,4,5,6,7,8$ \\
F. tricinctum & 4 \\
F. verticilloides & $1,2,3^{\star *}, 4^{\star *}$ \\
M. majus & $1,3^{\star \star}, 4^{\star *}$ \\
M. nivale &
\end{tabular}

Reference, location, cereal species, and identification method:

1 Xu et al. (2005): Hungary, Italy, Ireland, UK, wheat, PCR

2 Oerke et al. (2010): Germany, wheat, isolation

3 Nielsen et al. (2011): Denmark, wheat, barley, oat, triticale, rye, qPCR

4 Infantino et al. (2012): Italy, durum and bread wheat, freezing blotter method

5 Sundheim et al. (2013): Norway, wheat, barley, oat, isolation

6 Schöneberg et al. (2016): Switzerland, barley, isolation

7 Karlsson et al. (2017a): Sweden, wheat, metabarcoding

8 Beccari et al. (2018b): Italy, barley, isolation and molecular identification

*There are many more studies that have assessed the occurrence of different

Fusarium species in Europe. Here we iteratively added references that extended the list of reported species until no more species could be added. Therefore, many studies targeting only a handful of species were excluded. **These studies did not separate between the two Microdochium species.

Europe, which could be associated with the more frequent oat cultivation in Northern Europe (Aamot et al., 2015; Pasquali et al., 2016).

The situation with a complex of species causing or being associated with the disease rather than a single species, makes it more difficult to understand and manage FHB. Species within the FHB complex may have differences in their sensitivity to fungicides, leading to inconsistency in effects of chemical control (Pirgozliev et al., 2003). This also has implications when breeding for FHB resistance, as crop cultivars may differ in susceptibility, with lower sensitivity to one Fusarium species and not necessarily to another (Vogelgsang et al., 2008). There are, however, also examples of cultivars that show resistance against several Fusarium species (Linkmeyer et al., 2013).

Several Fusarium species can infect roots and crowns of cereals and cause FCR. The species are partly overlapping with those associated with FHB. It has been suggested that infected stem bases can be a source of inoculum for head infections (Parry et al., 1995). Tillmann et al. (2017) used isolation and identified F. culmorum, Fusarium equiseti, and Fusarium tricinctum, and to a lesser extent F. graminearum, Fusarium oxysporum, and F. avenaceum on stem bases in Germany. In their study, the colonization frequency of the different Fusarium spp. differed with crop rotation sequence. Shikur Gebremariam et al. (2018) isolated Fusarium fungi from the crown of wheat plants (bread wheat and durum wheat) from different regions of Turkey, and found 17 species, of which six were found to cause crown rot (F. avenaceum, F. culmorum, F. graminearum, Fusarium hostae, Fusarium pseudograminearum, and Fusarium redolens) whereas F. oxysporum, F. equiseti, Fusarium solani, Fusarium incarnatum (syn. Fusarium semitectum), Fusarium reticulatum (syn. Fusarium heterosporum), Fusarium flocciferum, Fusarium tricinctum, Fusarium brachygibbosum, Fusarium torulosum, Fusarium acuminatum, and Fusarium proliferatum were found not to cause any symptoms.

Although the FCR pathogens F. graminearum, F. culmorum, or F. pseudograminearum can grow systemically from infected crowns, they do not appear to colonize as far as to the head. However, DON is water-soluble and may be translocated to the heads without fungal growth indicating that FCR could be a potential additional source of DON. Beccari et al. (2018a) observed low amounts of DON translocated to the heads, but higher concentrations in stems. F. graminearum can also colonize the stem downwards from the heads (Guenther and Trail, 2005). An interesting observation made recently is that significant levels of DON originating from F. graminearum infections, was found in both wheat, barley and oat straw aimed for animal feed (Häggblom and Nordkvist, 2015). Late infection at least 20 days after anthesis caused toxin contamination of grain without clear disease symptoms on the spike (Siou et al., 2014). This suggests that control strategies that cover the late as well as early stage of grain development may be considered as an effective measure to reduce the final level of mycotoxins and may also reduce the risks for toxin contamination of the straw.

\section{Methods Targeting the FHB Species Complex}

The frequent occurrence of several Fusarium species in cereals makes monitoring more challenging. Isolation techniques for characterization of fungal communities are heavily biased toward fast-growing species and those favored by the growth medium and temperatures used for isolation. Until recently, molecular methods relied mostly on the identification of one species at a time. For example, Nicolaisen et al. (2009) presented individual real-time PCR assays for quantification of 11 Fusarium species. There are also examples of multiplex PCR for simultaneous molecular quantification of several Fusarium species, but these are limited to a handful of species (Bluhm et al., 2004; Yli-Mattila et al., 2008).

Metabarcoding is the current state-of-the-art technology for characterizing fungal communities. Recently, several metabarcoding approaches have been developed to characterize Fusarium communities in environmental samples (Table 2). Although some information about Fusarium can be obtained using metabarcoding targeting the fungal internal transcribed spacer (ITS), this gene does not provide species-level resolution 
TABLE 2 | Metabarcoding approaches targeting Fusarium communities in environmental samples.

\begin{tabular}{|c|c|c|c|c|c|}
\hline References & Target gene & Amplicon length (bp) & Fusarium-specific & Sequencing platform & Substrate \\
\hline LeBlanc et al. (2015) & RPB2 & 730 & no & 454 & rhizosphere \\
\hline Walder et al. (2017) & ITS-LSU & 1600 & no & PacBio SMRT & wheat, cover crops and maize \\
\hline Karlsson et al. (2016) & TEF- $1 \alpha$ & $550-600$ & yes & 454 & wheat kernels, soil \\
\hline Boutigny et al. (2019) & TEF- $1 \alpha$ & 640 & yes & Illumina Miseq 2×250 bp & cereal grain \\
\hline Cobo-Díaz et al. (2019) & TEF-1 $\alpha$ & 430 & yes & Illumina Miseq 2×300 bp & maize residues, soil \\
\hline
\end{tabular}

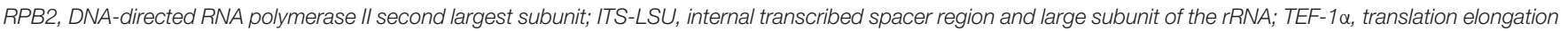
factor 1-alpha.

for Fusarium (Nicolaisen et al., 2014). Fusarium species are also known to carry non-orthologous copies of the ITS, which may hamper correct diversity estimation (O'Donnell and Cigelnik, 1997). In addition to the choice of marker gene, there are several sequencing platforms available. Early platforms included 454 sequencing which was outcompeted by techniques with higher output but shorter read length such as Illumina MiSeq. More recently, longer read lengths up to several kbp can be achieved with the so called third generation technologies such as the PacBio platform (Tedersoo et al., 2018; van Dijk et al., 2018). The major advantage of using longer read lengths is that it can improve taxonomic resolution (Singer et al., 2016).

Several combinations of marker genes and sequencing platforms have been used to characterize Fusarium communities (Table 2). LeBlanc et al. (2015) used primers targeting the partial DNA-directed RNA polymerase II second largest subunit (RPB2), enriching for taxa in the Sordariomycetes, in a metabarcoding study targeting Fusarium species in the rhizosphere, identifying about $13 \%$ of sequences as Fusarium. The first approach to use Fusarium-specific primers, targeted the elongation factor (TEF-1 $\alpha)$ which is single-copy in Fusarium, and was found to accurately reflect proportions of the different species (EdelHermann et al., 2015; Karlsson et al., 2016). Karlsson et al. (2017a) used this metabarcoding approach to describe the Fusarium community in wheat grains. In one specific year of sampling of 18 fields in Sweden, they found 12 operational taxonomic units (OTUs) belonging to nine Fusarium species. TEF-1 $\alpha$ amplicons were sequenced using 454 sequencing. However, long amplicons of the sizes obtained by these primers (550$600 \mathrm{bp}$ ) could for example be sequenced using PacBio SMRT sequencing. Recently, primers targeting a shorter portion of this region to match Illumina Miseq read length has been proposed (Cobo-Díaz et al., 2019). Another strategy was developed using long amplicons covering both the ITS and D1-D3 region of the large subunit sequenced on the PacBio SMRT platform, aiming to provide species-level information for Fusarium and information on the general fungal community (Walder et al., 2017). Walder et al. (2017) detected one OTU corresponding to F. avenaceum/tricinctum in wheat residues and nine Fusarium OTUs in maize in a field trial in Switzerland.

\section{Species Co-occurrences and Interactions}

The species within the FHB complex might have synergistic or competitive interactions influencing their development and ability to cause disease or produce mycotoxins. Xu X.-M. et al. (2007) and Xu X. et al. (2007) studied the response of four Fusarium species (F. avenaceum, F. culmorum, F. graminearum, and $F$. poae) upon co-inoculation on wheat plants under varying temperature and humidity conditions. They found that $F$. graminearum was the most competitive species over the environmental conditions tested, and $F$. poae the least competitive. There was a general increase in the production of mycotoxins upon co-inoculation compared to single species inoculations, also in situations where the pathogen DNA was decreased. The effect is, however, not universal, and the competitive ability of species or isolates seems to be a key factor in determining the outcome in terms of mycotoxin production. More competitive species, like F. graminearum, may increase their mycotoxin production at the expense of that by less competitive species such as F. culmorum or F. poae (Xu X. et al., 2007). Tan et al. (2020) showed that both FHB symptoms and mycotoxin levels on wheat heads pre-inoculated with $F$. poae were reduced compared to inoculation with of $F$. graminearum alone. The authors hypothesize that inoculations with the weak pathogen $F$. poae, that presented early induction of salisylic and jasmonic-related defenses, could potentially explain the suppression of a subsequent $F$. graminearum infection.

Interactions may also occur between different isolates or chemotypes of the same Fusarium species. Walkowiak et al. (2015) found that co-inoculation of two chemotypes of F. graminearum (3-acetyldeoxynivalenol and 15acetyldeoxynivalenol) resulted in reduced production of mycotoxins. Vaughan et al. (2020) compared single isolate inoculations to mixtures, of different isolates of F. graminearum of the same chemotype and population origin. Disease severity was found to be lower in mixed inoculations compared to single isolates, however, no consistent pattern was observed for DON contamination. The competitive ability is highly variable within species, complicating the possibility to tell whether different species (or chemotypes) vary in their ability to outcompete another species, or whether the differences are better explained at the level of isolates (Siou et al., 2015). The significance of competitive interactions for the mycotoxin accumulation highlights the importance of studies where the whole FHB species complex is considered, rather than regarding the disease and mycotoxin contamination as an interaction between a single pathogen and its host.

Under field conditions, both positive and negative correlations have been observed among Fusarium spp. Such correlations could be due to either similarities or differences in climatic 
preferences, or to interactions among species. Both Karlsson et al. (2017a) and Bernhoft et al. (2010) found that F. culmorum and $F$. sporotrichioides were positively correlated. Bernhoft et al. (2010) also found that F. graminearum was negatively correlated with $F$. avenaceum, F. culmorum, and $F$. poae, which might be an effect of its strong competitive ability when growing on wheat heads. Other negative or positive correlations between species have been reported from field investigations ( $\mathrm{Xu}$ et al., 2008; Bernhoft et al., 2010; Karlsson et al., 2017a).

Microdochium nivale and M. majus often co-occur with Fusarium and can also cause head blight. Several studies have indicated negative correlations between Fusarium and Microdochium species. Nielsen et al. (2011) found that M. nivale/majus occurred in $>90 \%$ of Danish grain samples, and grains had generally a higher biomass than grains infected with most Fusarium species, with the exception of F. graminearum. Although $M$. majus has been found to be highly abundant on lower wheat leaves, it can be almost absent from kernels where F. graminearum dominates (Waalwijk et al., 2004). Fungicide application decreasing the amount of Microdochium spp, have been found to result in increases of Fusarium spp. and associated mycotoxins (Simpson et al., 2001).

The Fusarium species patterns are variable, and it is still difficult to draw a conclusion on the general co-occurrence patterns of different Fusarium species. A synthesis is also made challenging by the variation in target species and methods used in the different studies. For a more comprehensive understanding of such patterns, additional field studies using metabarcoding approaches are needed, as well as controlled studies on interaction effects considering intra-species variability under variable environmental conditions.

\section{FHB DISEASE CYCLE AND THE CEREAL MICROBIOME}

Fusarium fungi may interact with the cereal microbiome at different stages of the FHB disease cycle and on different plant compartments (Figure 1). The plant harbors several specific niches for microbes, in connection to soil - in the roots and rhizosphere and on aboveground plant parts such as leaves, stems and heads. In general, the aboveground microbiome is less diverse than the rhizosphere microbiome (Leach et al., 2017). Nutrients are much scarcer on aboveground tissues and microbes are more exposed to environmental stress such as drought and UV-radiation. Annual crops have to be colonized during the growing season, while the soil offers many species an opportunity to survive saprotrophically. For aboveground plant parts, soil, air, seed and other plants are important as inoculum sources (Vorholt, 2012). While in the roots and rhizosphere, it is thought that plants recruit the microbiota from the surrounding soil. There is a succession of species during the growth season, where the plant is one factor shaping the microbiome due to root exudates (Chaparro et al., 2014) and leaking of nutrients from leaves. On leaves, the succession patterns over the growing season starts with bacteria followed by yeasts and finally filamentous fungi (Kinkel, 1997). It has furthermore been shown that phyllosphere bacterial diversity decrease over the growing season and that the community become more distinct from the soil microbiome over time (Copeland et al., 2015). The plant microbiome is further influenced by the environmental conditions such as weather, soil type and agricultural management (Fierer, 2017).

\section{Roots, Rhizosphere, and Stem Bases}

Fusarium fungi can be present in both seed, soil, and crop residues and act as inoculum for seedling blight, FCR and later also FHB. Root and rhizosphere microbiomes are influenced by plant species (Philippot et al., 2013). Cropping sequence may influence both the abundance of Fusarium inoculum and the abundance of potential antagonists present in the soil. Both will influence the health of the belowground plant parts. Borrell et al. (2016) characterized fungal communities in the roots of pulses and cereals. They found that the Fusarium species $F$. redolens and $F$. tricinctum were more abundant in pea roots than in wheat roots. Although pulses as preceding crop compared to wheat increased wheat productivity, no legacy effect was observed in root fungal communities of the following wheat crop. The same result was obtained by Esmaeili Taheri et al. (2016) characterizing fungal communities on durum wheat roots grown after different preceding crops. When isolates were classified into functional groups, it was found that more potential fungal antagonists, for example Trichoderma spp., were present on durum wheat roots after pea than after chickpea. In contrast, potential pathogens, including F. culmorum and F. acuminatum as well as other known root pathogens of wheat, were more abundant after one of the chickpea cultivars. The abundance of both functional groups was also correlated to wheat yield. Legacy effects of the preceding crop on fungal communities in the soil and roots of the following wheat crop was demonstrated in recent metabarcoding studies (Detheridge et al., 2016; Friberg et al., 2019). Some effects of previous wheat genotype on culturable and non-culturable bacteria in wheat rhizosphere have also been reported (Donn et al., 2015). The effects of crop genotype and cropping sequence were relatively small compared to the seasonal effects, leading the authors to suggest that selection of the right sampling scale is important for studying varietal effects on the structure and function of the rhizosphere microbiome (Donn et al., 2015). That the preceding crop influences the amount of Fusarium inoculum in the field is already known. This is due to the quality of the plant as a host for Fusarium. The above-mentioned studies indicate that also the abundance of other microorganisms may be affected, these microorganisms may have antagonistic interactions with Fusarium. Future studies could target the importance of the microbiome in preceding crop effects on Fusarium disease incidence.

Similarly to roots, stem bases are also plant compartments where Fusarium disease may occur and infected stem bases may increase the Fusarium inoculum in the field. In a study characterizing fungal communities on wheat plants using tRFLP, $M$. nivale and Oculimacula yallundae had a high incidence on stem bases, but decreased on stems, while the opposite was 
true for Davidiella and Cladosporium (Grudzinska-Sterno et al., 2016). The authors found positive associations between F. poae, F. avenaceum, and Fusarium spp. on stems, while Fusarium spp. correlated negatively with Parastagonospora nodorum and Zymoseptoria tritici. On stem bases, there was a positive correlation between F. avenaceum and P. nodorum. Several yeasts were also present in relatively high incidence (Grudzinska-Sterno et al., 2016), overlapping with those identified on leaves (Karlsson et al., 2014). Gdanetz and Trail (2017) found that bacterial diversity on wheat stems was comparable to that on leaves, but substantially lower than that on roots.

\section{Leaves}

The leaf is another potential point of interaction between Fusarium and the cereal microbiome. Fusarium species have limited ability to infect healthy leaves, but can cause symptoms in wounded leaves (Imathiu et al., 2009). However, gradual spread of Fusarium from stem bases, leaves and to the heads has been reported, with Fusarium sporulating on the leaves (Zinkernagel et al., 1997). Different cereal species harbor distinct leaf fungal communities and there is also differences between genotypes (Sapkota et al., 2015). One study on wheat found that location was more important in younger leaves, while cultivar was more important in older leaves (Sapkota et al., 2017). The mycobiome varies over the season, with Dothideomycetes increasing over plant maturity on wheat leaves (Gdanetz and Trail, 2017). Fungicide use has been reported to have relatively mild impact on the overall fungal communities on leaves (Karlsson et al., 2014; Sapkota et al., 2015). Knorr et al. (2019) showed that the total fungal abundance on leaves did not decrease after fungicide application but that relative abundance shifted in favor of yeasts, and pathogens able to infect late in the season. Köhl et al. (2007) identified only low amounts of Fusarium spp. on green leaves using qPCR. $M$. nivale was present on green leaves, while $F$. avenaceum was abundant on senescent leaves. Recent metabarcoding studies have not reported Fusarium spp. as a major part of the fungal leaf community in cereals (Karlsson et al., 2014, 2017b; Sapkota et al., 2015).

$\mathrm{Gu}$ et al. (2010) investigated the effect of fungicides on bacteria on wheat leaves using clone libraries and denaturing gradient gel electrophoresis (DGGE). Only $\gamma$-Proteobacteria were identified, including the Pseudomonas, Buchnera, and Pantoea genera. Fungicide use had an impact on bacterial communities and was associated with increased diversity. Using metabarcoding, many more phyla were identified from wheat leaves, stems and roots, Proteobacteria were identified as the most abundant phylum followed by Bacteriodetes and Firmicutes (Gdanetz and Trail, 2017).

\section{Heads}

It is well known that cereals heads differ in susceptibility to Fusarium infection over the season (Yoshida et al., 2007; Tekle et al., 2012; Siou et al., 2014). Several studies have investigated the fungal communities on cereal heads or harvested grain using metabarcoding. In a study in Denmark, an OTU corresponding to F. graminearum and closely related species was the most abundant OTU in wheat grain, followed by Alternaria infectoria. Two more Fusarium OTUs were among the top twenty (Nicolaisen et al., 2014). The authors identified three co-occurring clusters of OTUs, one consisting of saprotrophs, one of yeasts/saprotrophs and one of wheat pathogens. A study following the fungal community on wheat heads over the season found that the total amount of fungal DNA increased during head maturation. Simultaneously, the composition changed, so that the proportion of Ascomycota increased over Basidiomycota with time. Alternaria and Cladosporium were the most prevalent OTUs. Several Fusarium OTUs were identified but were not among the most abundant members of the community (Hertz et al., 2016). In a study on harvested wheat grain, Alternaria alternata and F. graminearum were isolated from all samples (González et al., 2008).

On fresh barley grains, Alternaria and several yeasts such as Cryptococcus were the most abundant (Chen et al., 2016). Fusarium and Alternaria relative abundance increased from fresh grain to malts, while yeasts and Cladosporium decreased. Interestingly, there was a higher fungal load on barley grains, including Fusarium, when the crop was harvested directly compared to swathing (Chen et al., 2016). Studies on the microbiome of oats are lacking although oats can be heavily contaminated with Fusarium mycotoxins, and with different Fusarium species than those on wheat (Hofgaard et al., 2016a; Edwards, 2017).

The bacterial community on cereal heads or grains is less wellcharacterized. In a study of wheat kernels, the most abundant phyla were Proteobacteria, Actinobacteria, Bacteroidetes and Firmicutes (Bakker and McCormick, 2019). Minervini et al. (2015) used metabarcoding of Firmicutes to target lactic acid bacteria in durum wheat roots, leaves and spikes throughout the growing season. The authors identified six core lactic acid bacterial genera present in $>98 \%$ of samples. Lactobacillus plantarum was present in all organs and at all growth stages as an endophyte. L. plantarum is also known as a promising biocontrol agent of FHB (Legrand et al., 2017).

Recent studies have characterized the structure of the cereal microbiome and the influence of different factors such as plant organ, management practices or environmental factors. Although there are significant variations, several fungal genera are repeatedly recovered from various geographical areas, suggesting that there is a core set of fungi adapted to cereals. Several ascomycetes, including Alternaria spp., Epicoccum spp., and Cladosporium spp. are among the most common fungi occupying the same niche as the FHB species complex on mature cereal heads and harvested grain. However, the ratio of Fusarium species to other fungi can vary greatly and the factors influencing this relationship are not fully understood. For instance, Alternaria and Fusarium have been found to have contrasting associations with microclimatic variables in a heterogenous wheat field, where Fusarium was related cooler and wetter spots while Alternaria abundance correlated to warmer and dryer places (Schiro et al., 2018). There is a need to closer examine the relative importance of biotic and abiotic interactions between Fusarium spp. and other fungal species for their success in colonizing cereal crops. 


\section{TOWARD MICROBIOME-BASED MANAGEMENT OF FHB}

There are many examples of beneficial microbial strains that can reduce plant diseases. By studying interactions between single microbial strains and pathogens, several mechanisms involved in disease suppression have been identified including, antibiosis, mycoparasitism, and competition. Beneficial microorganisms may also restrict pathogens indirectly, by affecting the plant, for instance by inducing resistance (Pieterse et al., 2014). From a microbiome perspective, these interactions become more complex and the possibility for indirect effects increases. A wellknown example of disease suppression where more complex mechanisms are involved is disease suppressive soils. Disease suppression can be specific, affecting only one pathogen, or more general restricting a broad range of pathogens. It has been proposed that specific disease suppression is linked to populations of antagonistic species, while the general suppression is due to more complex communities of microorganisms (Schlatter et al., 2017). Pathogen-microbiome interactions may also have negative outcomes for plant health. Microbial species ranging from commensal to pathogenic have been shown to facilitate infection or increase disease severity (Dewey et al., 1999; Jung et al., 2018; Seybold et al., 2020). Mechanisms can also be indirect, by suppressing plant defense (Seybold et al., 2020).

There are different strategies for exploiting plant-associated microbes to suppress or limit plant pathogens. One strategy is to identify individual beneficial species and apply these in crop production formulated in biocontrol products (augmentative biocontrol) (Sundh and Goettel, 2013). For FHB, biocontrol agents inoculated at the time of flowering is an attractive alternative to chemical control as the window of protection is narrow (Gilbert and Fernando, 2004). Many studies have evaluated such biocontrol agents to limit FHB (for a review see Legrand et al. (2017). A number of fungal and bacterial strains with biocontrol effect against FHB have been identified in genera such as Cryptococcus, Trichoderma, Clonostachys, Bacillus, Lactobacillus, Pseudomonas, and Streptomyces. Mycoparasitism has been suggested as the mode of action for some of the fungal genera including Trichoderma and Clonostachys (Karlsson et al., 2015). While production of antifungal secondary metabolites (antibiosis) has been the proposed mechanism for many of the bacterial antagonists (Zhao et al., 2014; Palazzini et al., 2016), but also for some fungal antagonists (Rodríguez et al., 2011). Nutrient competition through iron-chelating siderophores has been implied in antagonism against $F$. graminearum (Pal et al., 2001). Another example is the use of choline-metabolizing biocontrol strains, since choline is a compound present in wheat anthers which stimulates hyphal growth of $F$. graminearum (Schisler et al., 2006). Induced systemic resistance has been implied in the interaction between a Pseudomonas strain and root-infection by $F$. graminearum in barley (Henkes et al., 2011). Although many promising biocontrol agents against FHB have been identified, so far very few products have reached the market (Legrand et al., 2017). This may be due to difficulties in achieving consistent control effects under field conditions, challenges in the formulation process, and time-consuming and expensive approval processes (O'Callaghan, 2016; Sundh and Eilenberg, 2020).

Another biocontrol strategy is to focus on the indigenous microbial community, trying to stimulate an active and diverse community, often referred to as conservation biocontrol. There are also links between the augmentative and conservation biocontrol, for example it is important to understand the interactions of biocontrol agents with the indigenous microbiome (Massart et al., 2015). Developing consortia consisting of several biocontrol agents also requires understanding of species interactions.

In the following sections we will focus on studies addressing the potential for reducing Fusarium inoculum in crop residues by using biotic interactions and the potential for using the cereal microbiome in strategies to limit FHB development and mycotoxin contamination.

\section{Interactions on Crop Residues}

Due to the important role of crop residues as an inoculum source for FHB, many studies have targeted biological interactions on residues aiming to reduce survival of Fusarium spp. These interactions can affect both the survival of different Fusarium species and their ability to produce perithecia and ascospores or asexual conidia. A wide range of organisms will influence the ability of Fusarium spp. to survive on crop residues. Soil fauna are of importance because they feed on fungi colonizing the crop residues and directly on the residues, which enhances the decomposition process. Earthworms, especially the deepburrowing (anecic) species also take residues from the soil surface and pull them down into their burrows, thereby contributing to the removal of straw from the soil surface (Friberg et al., 2005). All these effects make earthworms contribute to the reduction of inoculum of Fusarium spp. surviving on the residues. Wolfarth et al. (2011) found for example that the anecic earthworm Lumbricus terrestris increased the incorporation of straw and reduced the biomass of F. culmorum under field conditions. Smaller soil animals like nematodes also feed selectively on residue colonizing fungi. Similarly to earthworms, they can directly reduce the biomass of certain species and change the competition and succession of species during the decomposition (Friberg et al., 2005).

Crop residues left on the soil surface have a slower decomposition rate than residues buried in the soil, which enables longer survival of Fusarium spp. on the residues. Pereyra et al. (2004) studied the survival of $F$. graminearum on straw buried in the soil or left on the surface and found that $25 \%$ of the dry matter remained after 24 months at the soil surface, compared to $2 \%$ after burial in the soil. In addition to this effect on the decomposition of straw, they found important effects from other organisms outcompeting $F$. graminearum. While being a strong competitor on the wheat head, $F$. graminearum seems to be a relatively weak competitor during saprotrophic growth, especially during later stages of decomposition (Fernandez et al., 2008; Leplat et al., 2012). Pereyra et al. (2004) found that F. graminearum decreased in abundance over time, while the abundance of other Fusarium species increased, suggesting that several other Fusarium spp. initially present in the straw (F. poae) 
or found in soil (F. oxysporum, F. solani) are better at colonizing the partially decomposed plant material than $F$. graminearum. Reduced survival of $F$. graminearum has also been associated with increases in antagonistic streptomycetes in soil following soil amendments of green manure (Perez et al., 2008). Legrand et al. (2019) measured the ability of F. graminearum to grow in soils from 31 wheat fields in France. They found that bacterial richness was lower in soils conducive to F. graminearum growth, and that conducive soils were richer in iron and manganese, compared to suppressive soils. The possibility to stimulate microbial degradation or antagonism against Fusarium spp. through cultural practices is a research field that should be explored further.

In addition to effects on the survival of Fusarium spp. on decomposing crop residues, microbial interactions can have an effect on the production of spores. Special interest in this field has been on reducing perithecia formation and ascospore production by inoculation of fungi with known biological control effects on Fusarium species or other plant pathogens. Isolates of Trichoderma harzianum (several isolates), Microsphaeropsis sp. (isolate P130A) or Clonostachys rosea (isolate ACM941) applied to crop residues have been shown to reduce perithecia formation of F. graminearum both under laboratory and field conditions (Fernandez, 1992; Bujold et al., 2001; Inch and Gilbert, 2007, 2011; Hue et al., 2009; Schöneberg et al., 2015). The mechanism behind the suppression by Microsphaeropsis sp. and C. rosea is not well understood. Schöneberg et al. (2015) saw that co-culturing on agar gave low prediction for the ability to reduce perithecia formation. In their study, the only isolate that could suppress perithecia formation when inoculated after F. graminearum (C. rosea) gave weak suppression in co-culture assays. In the suppression by $T$. harzianum, colonization of perithecia, especially before maturation, has been observed. It is also possible that secondary metabolites produced by $T$. harzianum interferes with perithecial development and potassium uptake, thereby preventing the build-up of osmotic pressure in the perithecia (Inch and Gilbert, 2011). Application of biological control fungi to crop residues might also have an effect on the formation of conidia. Luongo et al. (2005) found that C. rosea suppressed the conidia formation by F. culmorum, F. graminearum, F. proliferatum, and Fusarium verticillioides on wheat straw or maize stalks under controlled conditions, but that such effects were inconsistent under field conditions.

\section{Suppressiveness of the Cereal Microbiome}

Several studies have screened naturally occurring microorganisms on wheat for Fusarium suppression. Gdanetz and Trail (2017) screened endophytic fungi and bacteria in a biotest with F. graminearum on wheat seedlings and identified several strains reducing disease severity: Alternaria tenuissima and Alternaria sp., F. oxysporum, F. solani and Fusarium sp., Phoma sp. and Penicillium reticulisporum and Penicillium commune. In another example, starting with 758 isolates, 13 bacterial and fungal strains significantly reducing $F$. graminearum disease on detached wheat spikelets were identified (Comby et al., 2017), which belonged to the species Bacillus amyloliquefaciens, Aureobasidium protae, Clonostachys rosea, Microdochium bolleyi, Phoma glomerata, and Sarocladium kiliense (Comby et al., 2017). Another study isolated Pseudomonas bacteria from wheat leaves of which $15 \%$ showed antagonistic activity against $F$. graminearum or F. culmorum in vitro (Müller et al., 2016). Of the antagonists, $23 \%$ possessed the phlD gene, involved in the biosynthesis of 2,4-diacetylphloroglucinol (DAPG), an antibiotic with anti-fungal activity, indicating one possible mechanism of Fusarium suppression. A factor to consider is that different Fusarium isolates have been shown to respond very differently to antagonistic Pseudomonas strains (Müller et al., 2018). Most studies aim at identifying promising biocontrol agents, selecting among isolates in several steps, and do not aim to infer the overall level of suppressiveness of different plant compartments for example. This kind of comparisons would be interesting to identify cropping practices associated with a more suppressive microbiome. However, it has been reported that yeasts isolated from soil had better suppression against 16 fungal pathogens, including several Fusarium species, than those from the aboveground plant parts (Hilber-Bodmer et al., 2017).

As opposed to screening isolates for Fusarium suppression, several authors identified negative associations between Fusarium abundance and other microorganisms using molecular methods. Köhl et al. (2015) quantified initial abundance of eight Fusarium pathogens using $\mathrm{QPCR}$ and characterized the fungal and bacterial communities on maize stalks. After field exposure, large variation in the abundance of Fusarium species was observed between stalks. Several fungal and bacterial genera associated with stalks with lower Fusarium levels were identified including Cryptococcus spp., M. bolleyi, and several bacterial genera such as Bacillus and Pseudomonas. In another example on wheat spikes, fungal taxa Cladosporium, Itersonilia, and Holtermanniella had higher abundance on spikes lacking FHB symptoms (Rojas et al., 2020). A study on individual wheat kernels identified negative associations between mycotoxigenic Fusarium spp. and Sphingomonas (Bakker and McCormick, 2019). High Fusarium abundance was also linked to lower fungal and bacterial diversity in these two studies. Whether these observations are the result of active competition between species or an effect of environmental or plant factors is of interest to explore further.

Several studies have identified fungal species belonging to genera with many wheat pathogens as promising for biocontrol of FHB such as Microdochium, Alternaria, or Fusarium (Comby et al., 2017; Gdanetz and Trail, 2017). M. bolleyi is a common root endophyte of wheat and antagonistic against several root pathogens (Sieber and Grünig, 2006), although an effective antagonist in vitro it can also have deleterious effects in planta (Gdanetz and Trail, 2017). As was detailed before, Alternaria spp. are common on cereal heads, of which some are pathogenic and produce several mycotoxins (Lee et al., 2015). Effects of Fusarium and Alternaria species on each other was investigated on sterilized wheat kernels (Müller et al., 2014). Alternaria tenuissima grew slightly better in presence of Fusarium toxins, and was able to degrade both DON and ZEA. On the 
contrary, F. graminearum and F. culmorum could not degrade $A$. tenuissima toxins. In addition, F. graminearum and F. culmorum decreased and increased, respectively their production of ZEA in the presence of $A$. tenuissima toxins.

An interesting observation suggesting a role of competing microorganisms in FHB is that Fusarium infection may even be increased after fungicide application targeting foliar pathogens (Henriksen and Elen, 2005). However, studies testing the effect of competing saprotrophs on FHB in living plants have rendered variable results. Inoculation with Alternaria, Botrytis or Cladosporium at GS 69 (anthesis complete) before inoculation with F. culmorum reduced FHB severity (Liggitt et al., 1997). But in a similar experiment, when Alternaria, Cladosporium or Microdochium was inoculated as GS 57 (3/4 of inflorescence emerged) before F. culmorum inoculation FHB severity and DON concentration in grain increased (Pirgozliev et al., 2012).

Recently the importance of the microbiome for disease suppression as a community has been highlighted. For example, it was shown that a transplanted microbiome could transfer resistance to a foliar pathogen in another environment (Zahn and Amend, 2017). Another example is that leaf wash could restore pathogen resistance of cuticle mutants (Ritpitakphong et al., 2016). This kind of approaches directly manipulating the microbiome have not been explored in Fusarium cereal-pathosystems but could be a way forward to identify indicators for Fusarium-suppressive microbiomes or management strategies promoting disease suppressive indigenous communities.

Another interesting strategy is to incorporate the microbiome in breeding (Wei and Jousset, 2017). There are several examples from cereal crops demonstrating the impact of breeding on the root and rhizosphere microbiome (Alegria Terrazas et al., 2020; Kinnunen-Grubb et al., 2020). Valente et al. (2020) showed that root colonization by Pseudomonas kilonensis, a plant growth promoting rhizobacterium (PGPR), was higher in ancient wheat cultivars than in modern ones under gnotobiotic conditions. When a smaller set of cultivars were tested in non-sterile soil, there was no difference in colonization, but the same cultivars that had higher colonization in gnotobiotic conditions had enhanced root growth under water and nutrient stress in non-sterile soil. The authors hypothesize that dwarfism and the associated reduction in response to gibberellic acid in modern cultivars may be a trait affecting the interaction with PGPR. Identifying plant traits that are associated with the recruitment of a Fusariumsuppressive microbiome would be highly relevant. These traits could then be used as breeding targets. Beneficial microbes may also be introduced during reproduction so that they are vertically transmitted via the seed to coming generations (Mitter et al., 2017).

\section{CONCLUSION AND OUTLOOK}

It is clear that both interactions between the species responsible for $\mathrm{FHB}$, and interactions with other members of the plant microbiome play an important role in disease outbreaks and for mycotoxin accumulation in cereals. The ability to handle these problems would benefit greatly from a more thorough and detailed understanding about these interactions, and how such information can be implemented in prediction models and disease control programs. Today, we lack information about many key questions regarding how and when in the disease cycle of FHB these interactions can be utilized, to produce healthy crops with no or low mycotoxin contamination levels.

From our review we have identified several research needs. Much of the literature on FHB has a focus on F. graminearum on wheat, while problems are caused by several other species and in all cereal crops. There are examples that different Fusarium species may respond differently to control methods (Pirgozliev et al., 2003; Vogelgsang et al., 2008). Several regions have also experienced shifts in predominant species (ValverdeBogantes et al., 2019) and the legislation will likely cover more toxins produced by other species in the future. F. graminearum is interacting with other Fusarium species with differences in interactions depending on the crop species as well as on environmental conditions. New methods have been developed that will be highly valuable to assess the full diversity of the FHB species complex in different environments. For example, metabarcoding approaches (Table 2) are powerful tools to study co-occurrence patterns at different scales.

Observations of competitive interactions or negative associations between different Fusarium species and between Fusarium species and other members of the cereal microbiome are common. For instance, negative associations between Fusarium and other pathogenic fungi occupying the same niche such as Microdochium sp. and Alternaria sp. have been observed (Nielsen et al., 2011; Schiro et al., 2018). This could be due to contrasting environmental preferences or antagonistic or competitive interactions. Fusarium-antagonistic members in these taxa have indeed been isolated from cereals (Comby et al., 2017; Gdanetz and Trail, 2017). Mycotoxins may also play a role in species interactions and their ecological role should be further explored (Venkatesh and Keller, 2019). A better understanding of the mechanisms involved in species interactions and how these are influenced by the environmental conditions, is key to make accurate predictions of disease development and mycotoxin production. It may also give clues to which traits biocontrol agents should possess and under which conditions they should be applied in order to be most successful.

Several studies have in recent years evaluated the variation of the cereal microbiome structure over different plant organs, environmental conditions and management strategies (Donn et al., 2015; Gdanetz and Trail, 2017; Knorr et al., 2019). Cereal heads are relatively species poor compared to for instance soil or roots (Nicolaisen et al., 2014; Hertz et al., 2016; Friberg et al., 2019), and the relative competitive ability of Fusarium fungi differ among these microenvironments (Leplat et al., 2012). Disease control methods may be directed towards different stages of the FHB disease cycle such as reducing Fusarium survival in soil and in crop residues and limiting infection, growth 
or mycotoxin production on cereal heads. Microbiome-based strategies to limit FHB are still to be achieved and future studies are needed to identify the characteristics of cereal microbiomes linked to Fusarium suppression. Manipulating microbiomes or creating synthetic communities could be an approach to go from observations to a more mechanistic understanding (Vorholt et al., 2017).

Recent technological development has revolutionized our ability to characterize plant associated microbiomes on one hand, and to get in-depth insights into interactions between plant pathogens and their hosts or antagonists on the other hand. But there is a gap in knowledge between these two research fields that needs to be filled in order to use the potential of microbiomes in plant disease control, either through adding biocontrol agents to the crop, or through conservation biological control, where beneficial microbial populations are stimulated through carefully selected cropping practices or in resistance breeding strategies.

\section{REFERENCES}

Aamot, H. U., Ward, T. J., Brodal, G., Vrålstad, T., Larsen, G. B., Klemsdal, S. S., et al. (2015). Genetic and phenotypic diversity within the Fusarium graminearum species complex in Norway. Eur. J. Plant Pathol. 142, 501-519. doi: 10.1007/s10658-015-0629-4

Alegria Terrazas, R., Balbirnie-Cumming, K., Morris, J., Hedley, P. E., Russell, J., Paterson, E., et al. (2020). A footprint of plant eco-geographic adaptation on the composition of the barley rhizosphere bacterial microbiota. Sci. Rep. 10:12916. doi: 10.1038/s41598-020-69672-x

Bakker, M. G., and McCormick, S. P. (2019). Microbial correlates of Fusarium load and deoxynivalenol content in individual wheat Kernels. Phytopathology 109, 993-1002. doi: 10.1094/PHYTO-08-18-0310-R

Beccari, G., Arellano, C., Covarelli, L., Tini, F., Sulyok, M., and Cowger, C. (2019). Effect of wheat infection timing on Fusarium head blight causal agents and secondary metabolites in grain. Int. J. Food Microbiol. 290, 214-225. doi: 10. 1016/j.ijfoodmicro.2018.10.014

Beccari, G., Prodi, A., Pisi, A., Nipoti, P., Onofri, A., Nicholson, P., et al. (2018a). Development of three Fusarium crown rot causal agents and systemic translocation of deoxynivalenol following stem base infection of soft wheat. Plant Pathol. 67, 1055-1065. doi: 10.1111/ppa.12821

Beccari, G., Senatore, M. T., Tini, F., Sulyok, M., and Covarelli, L. (2018b). Fungal community, Fusarium head blight complex and secondary metabolites associated with malting barley grains harvested in Umbria, central Italy. Int. J. Food Microbiol. 273, 33-42. doi: 10.1016/j.ijfoodmicro.2018.03.005

Beccari, G., Prodi, A., Tini, F., Bonciarelli, U., Onofri, A., Oueslati, S., et al. (2017). Changes in the Fusarium head blight complex of malting barley in a three-year field experiment in Italy. Toxins 9:120. doi: 10.3390/toxins 9040120

Becher, R., Miedaner, T., and Wirsel, S. G. R. (2013). "Biology, diversity, and management of FHB-Causing Fusarium species in small-grain cereals," in Agricultural Applications The Mycota, ed. F. Kempken (Berlin: Springer Berlin Heidelberg), 199-241. doi: 10.1007/978-3-642-36821-9_8

Bernhoft, A., Clasen, P.-E., Kristoffersen, A. B., and Torp, M. (2010). Less Fusarium infestation and mycotoxin contamination in organic than in conventional cereals. Food Addit. Contam. Part A 27, 842-852. doi: 10.1080/ 19440041003645761

Beyer, M., Klix, M. B., Klink, H., and Verreet, J.-A. (2006). Quantifying the effects of previous crop, tillage, cultivar and triazole fungicides on the deoxynivalenol content of wheat grain - a review. J. Plant Dis. Prot. 113, 241-246.

Bilska, K., Jurczak, S., Kulik, T., Ropelewska, E., Olszewski, J., Żelechowski, M., et al. (2018). Species composition and trichothecene genotype profiling of Fusarium field isolates recovered from Wheat in Poland. Toxins 10:325. doi: $10.3390 /$ toxins 10080325

\section{AUTHOR CONTRIBUTIONS}

All authors planned the study, wrote the manuscript, and approved the final version of the manuscript.

\section{FUNDING}

Financial support was provided from the SLU Plant Protection Platform and by the European Union's Horizon 2020 Research and Innovation programme, under Grant Agreement No. 773554 (EcoStack).

\section{ACKNOWLEDGMENTS}

We thank Casja Lithell for Figure 1 and the SLU Plant Protection Platform focus group "Plant protection in cereal crops" for helpful discussions.

Bluhm, B. H., Cousin, M. A., and Woloshuk, C. P. (2004). Multiplex real-time PCR Detection of Fumonisin-producing and trichothecene-producing groups of Fusarium Species. J. Food Prot. 67, 536-543.

Borrell, A. N., Shi, Y., Gan, Y., Bainard, L. D., Germida, J. J., and Hamel, C. (2016). Fungal diversity associated with pulses and its influence on the subsequent wheat crop in the Canadian prairies. Plant Soil 414, 13-31. doi: 10.1007/s11104016-3075-y

Bottalico, A., and Perrone, G. (2002). Toxigenic Fusarium species and mycotoxins associated with head blight in small-grain cereals in Europe. Eur. J. Plant Pathol. 108, 611-624. doi: 10.1023/A:1020635214971

Boutigny, A.-L., Gautier, A., Basler, R., Dauthieux, F., Leite, S., Valade, R., et al. (2019). Metabarcoding targeting the EF1 alpha region to assess Fusarium diversity on cereals. PLoS One 14:e0207988. doi: 10.1371/journal.pone.0207988

Brennan, J. M., Leonard, G., Cooke, B. M., and Doohan, F. M. (2005). Analysis of head and leaf reaction towards Microdochium nivale. Eur. J. Plant Pathol. 112, 79-83. doi: 10.1007/s10658-004-5849-y

Bujold, I., Paulitz, T. C., and Carisse, O. (2001). Effect of Microsphaeropsis sp. on the production of perithecia and ascospores of Gibberella zeae. Plant Dis. 85, 977-984. doi: 10.1094/PDIS.2001.85.9.977

Chaparro, J. M., Badri, D. V., and Vivanco, J. M. (2014). Rhizosphere microbiome assemblage is affected by plant development. ISME J. 8, 790-803. doi: 10.1038/ ismej.2013.196

Chen, W., Turkington, T. K., Lévesque, C. A., Bamforth, J. M., Patrick, S. K., Lewis, C. T., et al. (2016). Geography and agronomical practices drive diversification of the epiphytic mycoflora associated with barley and its malt end product in western Canada. Agric. Ecosyst. Environ. 226, 43-55. doi: 10.1016/j.agee.2016. 03.030

Cobo-Díaz, J. F., Baroncelli, R., Le Floch, G., and Picot, A. (2019). A novel metabarcoding approach to investigate Fusarium species composition in soil and plant samples. FEMS Microbiol. Ecol. 95:fiz084. doi: 10.1093/femsec/fiz084

Comby, M., Gacoin, M., Robineau, M., Rabenoelina, F., Ptas, S., Dupont, J., et al. (2017). Screening of wheat endophytes as biological control agents against Fusarium head blight using two different in vitro tests. Microbiol. Res. 202, 11-20. doi: 10.1016/j.micres.2017.04.014

Copeland, J. K., Yuan, L., Layeghifard, M., Wang, P. W., and Guttman, D. S. (2015). Seasonal community succession of the phyllosphere microbiome. Mol. Plant. Microbe Interact. 28, 274-285. doi: 10.1094/MPMI-10-14-0331-FI

Detheridge, A. P., Brand, G., Fychan, R., Crotty, F. V., Sanderson, R., Griffith, G. W., et al. (2016). The legacy effect of cover crops on soil fungal populations in a cereal rotation. Agric. Ecosyst. Environ. 228, 49-61. doi: 10.1016/j.agee.2016. 04.022

Dewey, F. M., Wong, Y. L., Seery, R., Hollins, T. W., and Gurr, S. J. (1999). Bacteria associated with Stagonospora (Septoria) nodorum increase pathogenicity of the fungus. New Phytol. 144, 489-497. 
Dill-Macky, R., and Jones, R. K. (2000). The effect of previous crop residues and tillage on Fusarium head blight of wheat. Plant Dis. 84, 71-76. doi: 10.1094/ PDIS.2000.84.1.71

Donn, S., Kirkegaard, J. A., Perera, G., Richardson, A. E., and Watt, M. (2015). Evolution of bacterial communities in the wheat crop rhizosphere. Environ. Microbiol. 17, 610-621. doi: 10.1111/1462-2920.12452

Edel-Hermann, V., Gautheron, N., Mounier, A., and Steinberg, C. (2015). Fusarium diversity in soil using a specific molecular approach and a cultural approach. J. Microbiol. Methods 111, 64-71. doi: 10.1016/j.mimet.2015.01.026

Edwards, S. G. (2017). Impact of agronomic and climatic factors on the mycotoxin content of harvested oats in the United Kingdom. Food Addit. Contam. Part A 34, 2230-2241. doi: 10.1080/19440049.2017.1372639

Edwards, S. G., and Jennings, P. (2018). Impact of agronomic factors on Fusarium mycotoxins in harvested wheat. Food Addit. Contam. Part A 35, 2443-2454. doi: 10.1080/19440049.2018.1543954

Esmaeili Taheri, A., Hamel, C., and Gan, Y. (2016). Cropping practices impact fungal endophytes and pathogens in durum wheat roots. Appl. Soil Ecol. 100, 104-111. doi: 10.1016/j.apsoil.2015.12.007

European Commission (2006). Commission Regulation (EC) No 1881/2006. Brussels: European Commission, 5-24. OJ 36420122006.

Fernandez, M., Huber, D., Basnyat, P., and Zentner, R. (2008). Impact of agronomic practices on populations of Fusarium and other fungi in cereal and noncereal crop residues on the Canadian Prairies. Soil Tillage Res. 100, 60-71. doi: 10. 1016/j.still.2008.04.008

Fernandez, M. R. (1992). The effect of Trichoderma harzianum on fungal pathogens infesting wheat and black oat straw. Soil Biol. Biochem. 24, 10311034. doi: 10.1016/0038-0717(92)90032-S

Fierer, N. (2017). Embracing the unknown: disentangling the complexities of the soil microbiome. Nat. Rev. Microbiol. 15:nrmicro.2017.87. doi: 10.1038/ nrmicro.2017.87

Fraeyman, S., Croubels, S., Devreese, M., and Antonissen, G. (2017). Emerging Fusarium and Alternaria mycotoxins: occurrence. Toxicity and Toxicokinetics. Toxins 9:228. doi: 10.3390/toxins9070228

Friberg, H., Lagerlöf, J., and Rämert, B. (2005). Influence of soil fauna on fungal plant pathogens in agricultural and horticultural systems. Biocontrol Sci. Technol. 15, 641-658. doi: 10.1080/09583150500086979

Friberg, H., Persson, P., Jensen, D. F., and Bergkvist, G. (2019). Preceding crop and tillage system affect winter survival of wheat and the fungal communities on young wheat roots and in soil. FEMS Microbiol. Lett. 366:fnz189. doi: 10.1093/ femsle/fnz189

Gavrilova, O. P., Orina, A. S., Kessenikh, E. D., Gustyleva, L. K., Savelieva, E. I., Gogina, N. N., et al. (2020). Diversity of physiological and biochemical characters of Microdochium Fungi. Chem. Biodivers. 17:e2000294. doi: 10.1002/ cbdv.202000294

Gdanetz, K., and Trail, F. (2017). The wheat microbiome under four management strategies, and potential for endophytes in disease protection. Phytobiomes 1:PBIOMES-05-17-0023-R. doi: 10.1094/PBIOMES-05-17-0023-R

Geiser, D. M., Aoki, T., Bacon, C. W., Baker, S. E., Bhattacharyya, M. K., Brandt, M. E., et al. (2013). One fungus, one name: defining the genus Fusarium in a scientifically robust way that preserves longstanding use. Phytopathology 103, 400-408. doi: 10.1094/PHYTO-07-12-0150-LE

Gilbert, J., and Fernando, W. G. D. (2004). Epidemiology and biological control of Gibberella zeae / Fusarium graminearum. Can. J. Plant Pathol. 26, 464-472. doi: 10.1080/07060660409507166

González, H. H. L., Moltó, G. A., Pacin, A., Resnik, S. L., Zelaya, M. J., Masana, M., et al. (2008). Trichothecenes and mycoflora in wheat harvested in nine locations in buenos aires province. Argentina. Mycopathologia 165, 105-114. doi: 10.1007/s11046-007-9084-x

Grudzinska-Sterno, M., Yuen, J., Stenlid, J., and Djurle, A. (2016). Fungal communities in organically grown winter wheat affected by plant organ and development stage. Eur. J. Plant Pathol. 146, 1-17. doi: 10.1007/s10658-0160927-5

Gu, L., Bai, Z., Jin, B., Hu, Q., Wang, H., Zhuang, G., et al. (2010). Assessing the impact of fungicide enostroburin application on bacterial community in wheat phyllosphere. J. Environ. Sci. 22, 134-141. doi: 10.1016/S1001-0742(09) 60084-X

Guenther, J. C., and Trail, F. (2005). The development and differentiation of Gibberella zeae (anamorph: Fusarium graminearum) during colonization of wheat. Mycologia 97, 229-237. doi: 10.1080/15572536.2006.1183 2856

Häggblom, P., and Nordkvist, E. (2015). Deoxynivalenol, zearalenone, and Fusarium graminearum contamination of cereal straw; field distribution; and sampling of big bales. Mycotoxin Res. 31, 101-107. doi: 10.1007/s12550-0150220-z

Heier, T., Jain, S. K., Kogel, K.-H., and Pons-Kühnemann, J. (2005). Influence of N-fertilization and fungicide strategies on Fusarium head blight severity and mycotoxin content in winter wheat. J. Phytopathol. 153, 551-557. doi: 10.1111/j.1439-0434.2005.01021.x

Hellin, P., Duvivier, M., Dedeurwaerder, G., Bataille, C., Proft, M. D., and Legrève, A. (2018). Evaluation of the temporal distribution of Fusarium graminearum airborne inoculum above the wheat canopy and its relationship with Fusarium head blight and DON concentration. Eur. J. Plant Pathol. 151, 1-16. doi: 10. 1007/s10658-018-1442-7

Henkes, G. J., Jousset, A., Bonkowski, M., Thorpe, M. R., Scheu, S., Lanoue, A., et al. (2011). Pseudomonas fluorescens CHA0 maintains carbon delivery to Fusarium graminearum-infected roots and prevents reduction in biomass of barley shoots through systemic interactions. J. Exp. Bot. 62, 4337-4344. doi: $10.1093 /$ jxb/err149

Henriksen, B., and Elen, O. (2005). Natural Fusarium grain infection level in wheat, barley and oat after early application of fungicides and herbicides. J. Phytopathol. 153, 214-220. doi: 10.1111/j.1439-0434.2005.00955.x

Hertz, M., Jensen, I. R., Jensen, L. Ø, Thomsen, S. N., Winde, J., Dueholm, M. S., et al. (2016). The fungal community changes over time in developing wheat heads. Int. J. Food Microbiol. 222, 30-39. doi: 10.1016/j.ijfoodmicro.2016.01. 018

Hilber-Bodmer, M., Schmid, M., Ahrens, C. H., and Freimoser, F. M. (2017). Competition assays and physiological experiments of soil and phyllosphere yeasts identify Candida subhashii as a novel antagonist of filamentous fungi. BMC Microbiol. 17:4. doi: 10.1186/s12866-016-0908-z

Hofer, K., Barmeier, G., Schmidhalter, U., Habler, K., Rychlik, M., Hückelhoven, R. et al. (2016). Effect of nitrogen fertilization on Fusarium head blight in spring barley. Crop Prot. 88, 18-27. doi: 10.1016/j.cropro.2016.05.007

Hofer, K., Hückelhoven, R., and Hess, M. (2019). Analysis of archive samples of spring and winter barley support an increase in individual Fusarium species in Bavarian barley grain over the last decades. J. Plant Dis. Prot. 126, 247-254. doi: 10.1007/s41348-019-00220-0

Hofgaard, I. S., Aamot, H. U., Torp, T., Jestoi, M., Lattanzio, V. M. T., Klemsdal, S. S., et al. (2016a). Associations between Fusarium species and mycotoxins in oats and spring wheat from farmers' fields in Norway over a six-year period. World Mycotoxin. J. 9, 365-378. doi: 10.3920/WMJ2015.2003

Hofgaard, I. S., Seehusen, T., Aamot, H. U., Riley, H., Razzaghian, J., Le, V. H., et al. (2016b). Inoculum potential of Fusarium spp. relates to tillage and straw management in norwegian fields of Spring Oats. Front. Microbiol. 7:556. doi: $10.3389 /$ fmicb. 2016.00556

Hol, W. H. G., Garbeva, P., Hordijk, C., Hundscheid, M. P. J., Gunnewiek, P. J. A. K., van Agtmaal, M., et al. (2015). Non-random species loss in bacterial communities reduces antifungal volatile production. Ecology 96, 2042-2048. doi: 10.1890/14-2359.1

Hooker, D. C., Schaafsma, A. W., and Tamburic-Ilincic, L. (2002). Using weather variables pre- and post-heading to predict deoxynivalenol content in winter wheat. Plant Dis. 86, 611-619. doi: 10.1094/PDIS.2002.86.6.611

Hu, J., Wei, Z., Friman, V.-P., Gu, S., Wang, X., Eisenhauer, N., et al. (2016). Probiotic diversity enhances rhizosphere microbiome function and plant disease suppression. mBio 7, e1790-e1716. doi: 10.1128/mBio.017 90-16

Hue, A. G., Voldeng, H. D., Savard, M. E., Fedak, G., Tian, X., and Hsiang, T. (2009). Biological control of Fusarium head blight of wheat with Clonostachys rosea strain ACM941. Can. J. Plant Pathol. 31, 169-179. doi: 10.1080/ 07060660909507590

Imathiu, S. M., Edwards, S. G., Ray, R. V., and Back, M. A. (2013). Fusarium langsethiae - a HT-2 and T-2 toxins producer that needs more attention. J. Phytopathol. 161, 1-10. doi: 10.1111/jph.12036

Imathiu, S. M., Ray, R. V., Back, M., Hare, M. C., and Edwards, S. G. (2009). Fusarium langsethiae pathogenicity and aggressiveness towards oats and wheat in wounded and unwounded in vitro detached leaf assays. Eur. J. Plant Pathol. 124, 117-126. doi: 10.1007/s10658-008-9398-7 
Inch, S., and Gilbert, J. (2007). Effect of Trichoderma harzianum on perithecial production of Gibberella zeae on wheat straw. Biocontrol Sci. Technol. 17, 635-646. doi: 10.1080/09583150701408865

Inch, S., and Gilbert, J. (2011). Scanning electron microscopy observations of the interaction between Trichoderma harzianum and perithecia of Gibberella zeae. Mycologia 103, 1-9. doi: 10.3852/09-285

Infantino, A., Santori, A., and Shah, D. A. (2012). Community structure of the Fusarium complex on wheat seed in Italy. Eur. J. Plant Pathol. 132, 499-510. doi: 10.1007/s10658-011-9892-1

Jennings, P., Coates, M. E., Walsh, K., Turner, J. A., and Nicholson, P. (2004). Determination of deoxynivalenol- and nivalenol-producing chemotypes of Fusarium graminearum isolated from wheat crops in England and Wales. Plant Pathol. 53, 643-652. doi: 10.1111/j.0032-0862.2004.01061.x

Jung, B., Park, J., Kim, N., Li, T., Kim, S., Bartley, L. E., et al. (2018). Cooperative interactions between seed-borne bacterial and air-borne fungal pathogens on rice. Nat. Commun. 9:31. doi: 10.1038/s41467-017-02430-2

Karlsson, I., Edel-Hermann, V., Gautheron, N., Durling, M. B., Kolseth, A.-K., Steinberg, C., et al. (2016). Genus-specific primers for study of Fusarium communities in field samples. Appl. Environ. Microbiol. 82, 491-501. doi: 10. 1128/AEM.02748-15

Karlsson, I., Friberg, H., Kolseth, A.-K., Steinberg, C., and Persson, P. (2017a). Agricultural factors affecting Fusarium communities in wheat kernels. Int. J. Food Microbiol. 252, 53-60. doi: 10.1016/j.ijfoodmicro.2017.04.011

Karlsson, I., Friberg, H., Kolseth, A.-K., Steinberg, C., and Persson, P. (2017b). Organic farming increases richness of fungal taxa in the wheat phyllosphere. Mol. Ecol. 26, 3424-3436. doi: 10.1111/mec.14132

Karlsson, I., Friberg, H., Steinberg, C., and Persson, P. (2014). Fungicide effects on fungal community composition in the wheat Phyllosphere. PLoS One 9:e111786. doi: 10.1371/journal.pone.0111786

Karlsson, M., Durling, M. B., Choi, J., Kosawang, C., Lackner, G., Tzelepis, G. D., et al. (2015). Insights on the evolution of mycoparasitism from the genome of Clonostachys rosea. Genome Biol. Evol. 7, 465-480. doi: 10.1093/gbe/evu292

Kazan, K., Gardiner, D. M., and Manners, J. M. (2012). On the trail of a cereal killer: recent advances in Fusarium graminearum pathogenomics and host resistance. Mol. Plant Pathol. 13, 399-413. doi: 10.1111/j.1364-3703.2011.00762.x

Keller, M. D., Bergstrom, G. C., and Shields, E. J. (2014). The aerobiology of Fusarium graminearum. Aerobiologia 30, 123-136. doi: 10.1007/s10453-0139321-3

Kelly, A. C., and Ward, T. J. (2018). Population genomics of Fusarium graminearum reveals signatures of divergent evolution within a major cereal pathogen. PLoS One 13:e0194616. doi: 10.1371/journal.pone.0194616

Kinkel, L. L. (1997). Microbial population dynamics on leaves. Annu. Rev. Phytopathol. 35, 327-347. doi: 10.1146/annurev.phyto.35.1.327

Kinnunen-Grubb, M., Sapkota, R., Vignola, M., Nunes, I. M., and Nicolaisen, M. (2020). Breeding selection imposed a differential selective pressure on the wheat root-associated microbiome. FEMS Microbiol. Ecol. 96:fiaa196. doi: 10.1093/ femsec/fiaa196

Knorr, K., Jørgensen, L. N., and Nicolaisen, M. (2019). Fungicides have complex effects on the wheat phyllosphere mycobiome. PLoS One 14:e213176. doi: 10.1371/journal.pone.0213176

Knutsen, H.-K., Barregård, L., Bignami, M., Brüschweiler, B., Ceccatelli, S., Cottrill, B., et al. (2017). Appropriateness to set a group health based guidance value for T2 and HT2 toxin and its modified forms. EFSA J. 15:e04655. doi: 10.2903/j. efsa.2017.4655

Köhl, J., de Haas, B. H., Kastelein, P., Burgers, S. L. G. E., and Waalwijk, C. (2007). Population dynamics of Fusarium spp. and Microdochium nivale in crops and crop residues of winter wheat. Phytopathology 97, 971-978. doi: 10.1094/PHYTO-97-8-0971

Köhl, J., Lombaers, C., Moretti, A., Bandyopadhyay, R., Somma, S., and Kastelein, P. (2015). Analysis of microbial taxonomical groups present in maize stalks suppressive to colonization by toxigenic Fusarium spp.: a strategy for the identification of potential antagonists. Biol. Control 83, 20-28. doi: 10.1016/j. biocontrol.2014.12.007

Kosiak, B., Torp, M., Skjerve, E., and Thrane, U. (2003). The prevalence and distribution of Fusarium species in norwegian cereals: a survey. Acta Agric. Scand. Sect. B Soil Plant Sci. 53, 168-176. doi: 10.1080/09064710310018118

Leach, J. E., Triplett, L. R., Argueso, C. T., and Trivedi, P. (2017). Communication in the phytobiome. Cell 169, 587-596. doi: 10.1016/j.cell.2017.04.025
LeBlanc, N., Kinkel, L. L., and Kistler, H. C. (2015). Soil fungal communities respond to grassland plant community richness and soil edaphics. Microb. Ecol. 70, 188-195. doi: 10.1007/s00248-014-0531-1

Lee, H. B., Patriarca, A., and Magan, N. (2015). Alternaria in food: ecophysiology, mycotoxin production and toxicology. Mycobiology 43, 93-106. doi: 10.5941/ MYCO.2015.43.2.93

Legrand, F., Chen, W., Cobo-Díaz, J. F., Picot, A., and Floch, G. L. (2019). Co-occurrence analysis reveal that biotic and abiotic factors influence soil fungistasis against Fusarium graminearum. FEMS Microbiol. Ecol. 95:fiz056. doi: 10.1093/femsec/fiz056

Legrand, F., Picot, A., Cobo-Díaz, J. F., Chen, W., and Le Floch, G. (2017). Challenges facing the biological control strategies for the management of Fusarium Head Blight of cereals caused by F. graminearum. Biol. Control 113, 26-38. doi: 10.1016/j.biocontrol.2017.06.011

Lemmens, M., Haim, K., Lew, H., and Ruckenbauer, P. (2004). The effect of nitrogen fertilization on Fusarium head blight development and deoxynivalenol contamination in wheat. J. Phytopathol. 152, 1-8. doi: 10.1046/j.1439-0434. 2003.00791.x

Leplat, J., Friberg, H., Abid, M., and Steinberg, C. (2012). Survival of Fusarium graminearum, the causal agent of Fusarium head blight. A review. Agron. Sustain. Dev. 33, 97-111. doi: 10.1007/s13593-012-0098-5

Leslie, J. F., and Summerell, B. A. (2006). Fusarium Laboratory Manual. Ames, IA: Blackwell Publishing.

Liddell, C. (2003). "Systematics of Fusarium species and allies associated with Fusarium head blight," in Fusarium Head Blight of Wheat and Barley, eds K. Leonard and W. Bushnell (St. Paul: APS), 35-43.

Liggitt, J., Jenkinson, P., and Parry, D. W. (1997). The role of saprophytic microflora in the development of Fusarium ear blight of winter wheat caused by Fusarium culmorum. Crop Prot. 16, 679-685. doi: 10.1016/S0261-2194(97) 00039-2

Linkmeyer, A., Götz, M., Hu, L., Asam, S., Rychlik, M., Hausladen, H., et al. (2013). Assessment and introduction of quantitative resistance to Fusarium head blight in elite spring barley. Phytopathology ${ }^{\circledR} 103,1252-1259$. doi: 10.1094/PHYTO02-13-0056-R

Luongo, L., Galli, M., Corazza, L., Meekes, E., Haas, L. D., Van Der Plas, C. L., et al. (2005). Potential of fungal antagonists for biocontrol of Fusarium spp. in wheat and maize through competition in crop debris. Biocontrol Sci. Technol. 15, 229-242. doi: 10.1080/09583150400016852

Maldonado-Ramirez, S. L., Schmale, D. G., Shields, E. J., and Bergstrom, G. C. (2005). The relative abundance of viable spores of Gibberella zeae in the planetary boundary layer suggests the role of long-distance transport in regional epidemics of Fusarium head blight. Agric. For. Meteorol. 132, 20-27. doi: 10. 1016/j.agrformet.2005.06.007

Massart, S., Martinez-Medina, M., and Jijakli, M. H. (2015). Biological control in the microbiome era: challenges and opportunities. Biol. Control 89, 98-108. doi: 10.1016/j.biocontrol.2015.06.003

Minervini, F., Celano, G., Lattanzi, A., Tedone, L., Mastro, G. D., Gobbetti, M., et al. (2015). Lactic acid bacteria in durum wheat flour are endophytic components of the plant during its entire life cycle. Appl. Environ. Microbiol. 81, 6736-6748. doi: 10.1128/AEM.01852-15

Mitter, B., Pfaffenbichler, N., Flavell, R., Compant, S., Antonielli, L., Petric, A., et al. (2017). A new approach to modify plant microbiomes and traits by introducing beneficial bacteria at flowering into progeny seeds. Front. Microbiol. 8:11. doi: 10.3389/fmicb.2017.00011

Mitter, V., Francl, L. J., Ali, S., Simpfendorfer, S., and Chakraborty, S. (2006). Ascosporic and conidial inoculum of Gibberella zeae play different roles in Fusarium head blight and crown rot of wheat in Australia and the USA. Australas. Plant Pathol. 35, 441-452. doi: 10.1071/AP06046

Morrison, E., Kosiak, B., Ritieni, A., Aastveit, A. H., Uhlig, S., and Bernhoft, A. (2002). Mycotoxin production by Fusarium avenaceum strains isolated from norwegian grain and the cytotoxicity of rice culture extracts to porcine kidney epithelial cells. J. Agric. Food Chem. 50, 3070-3075. doi: 10.1021/jf011532h

Müller, M. E. H., Urban, K., Köppen, R., Siegel, D., Korn, U., and Koch, M. (2014). Mycotoxins as antagonistic or supporting agents in the interaction between phytopathogenic Fusarium and Alternaria fungi. World Mycotoxin J. 8, 311-321. doi: 10.3920/WMJ2014.1747

Müller, T., Behrendt, U., Ruppel, S., von der Waydbrink, G., and Müller, M. E. H. (2016). Fluorescent pseudomonads in the phyllosphere of wheat: potential 
antagonists against fungal phytopathogens. Curr. Microbiol. 72, 383-389. doi: 10.1007/s00284-015-0966-8

Müller, T., Ruppel, S., Behrendt, U., Lentzsch, P., and Müller, M. E. H. (2018) Antagonistic potential of fluorescent pseudomonads colonizing wheat heads against mycotoxin producing Alternaria and Fusaria. Front. Microbiol. 9:2124. doi: 10.3389/fmicb.2018.02124

Nicolaisen, M., Justesen, A. F., Knorr, K., Wang, J., and Pinnschmidt, H. O. (2014). Fungal communities in wheat grain show significant co-existence patterns among species. Fungal Ecol. 11, 145-153. doi: 10.1016/j.funeco.2014.06.002

Nicolaisen, M., Supronienë, S., Nielsen, L. K., Lazzaro, I., Spliid, N. H., and Justesen, A. F. (2009). Real-time PCR for quantification of eleven individual Fusarium species in cereals. J. Microbiol. Methods 76, 234-240. doi: 10.1016/j.mimet.2008. 10.016

Nielsen, L. K., Jensen, J. D., Nielsen, G. C., Jensen, J. E., Spliid, N. H., Thomsen, I. K., et al. (2011). Fusarium Head blight of cereals in denmark: species complex and related Mycotoxins. Phytopathology 101, 960-969. doi: 10.1094/PHYTO07-10-0188

O'Callaghan, M. (2016). Microbial inoculation of seed for improved crop performance: issues and opportunities. Appl. Microbiol. Biotechnol. 100, 57295746. doi: 10.1007/s00253-016-7590-9

O’Donnell, K., and Cigelnik, E. (1997). Two divergent intragenomic rDNA ITS2 types within a monophyletic lineage of the fungus Fusarium are nonorthologous. Mol. Phylogenet. Evol. 7, 103-116. doi: 10.1006/mpev.1996. 0376

Oerke, E.-C., Meier, A., Dehne, H.-W., Sulyok, M., Krska, R., and Steiner, U. (2010). Spatial variability of Fusarium head blight pathogens and associated mycotoxins in wheat crops. Plant Pathol. 59, 671-682. doi: 10.1111/j.1365-3059.2010 02286.x

Pal, K. K., Tilak, K. V. B. R., Saxcna, A. K., Dey, R., and Singh, C. S. (2001). Suppression of maize root diseases caused by Macrophomina phaseolina, Fusarium moniliforme and Fusarium graminearum by plant growth promoting rhizobacteria. Microbiol. Res. 156, 209-223. doi: 10.1078/0944-5013-00103

Palazzini, J. M., Dunlap, C. A., Bowman, M. J., and Chulze, S. N. (2016). Bacillus velezensis RC 218 as a biocontrol agent to reduce Fusarium head blight and deoxynivalenol accumulation: genome sequencing and secondary metabolite cluster profiles. Microbiol. Res. 192, 30-36. doi: 10.1016/j.micres.2016.06.002

Parikka, P., Hakala, K., and Tiilikkala, K. (2012). Expected shifts in Fusarium species' composition on cereal grain in Northern Europe due to climatic change. Food Addit. Contam. Part A 29, 1543-1555. doi: 10.1080/19440049. 2012.680613

Parry, D. W., Jenkinson, P., and McLeod, L. (1995). Fusarium ear blight (scab) in small grain cereals - a review. Plant Pathol. 44, 207-238. doi: 10.1111/j.13653059.1995.tb02773.x

Pasquali, M., Beyer, M., Logrieco, A., Audenaert, K., Balmas, V., Basler, R., et al. (2016). A European database of Fusarium graminearum and F. culmorum trichothecene genotypes. Front. Microbiol. 7:406. doi: 10.3389/fmicb.2016. 00406

Pereyra, S. A., Dill-Macky, R., and Sims, A. L. (2004). Survival and inoculum production of Gibberella zeae in wheat residue. Plant Dis. 88, 724-730. doi: 10.1094/PDIS.2004.88.7.724

Perez, C., Dill-Macky, R., and Kinkel, L. L. (2008). Management of soil microbial communities to enhance populations of Fusarium graminearum-antagonists in soil. Plant Soil 302, 53-69. doi: 10.1007/s11104-007-9455-6

Persson, P., and Bötker, H. (2014). "Seed borne Fusarium graminearum in cereals introduction to new areas," in NJF Seminar 478 Nordic-Baltic Fusarium seminar, (Helsinki, FL: NJF). NJF Report.

Philippot, L., Raaijmakers, J. M., Lemanceau, P., and van der Putten, W. H. (2013). Going back to the roots: the microbial ecology of the rhizosphere. Nat. Rev. Microbiol. 11, 789-799. doi: 10.1038/nrmicro3109

Pieterse, C. M. J., Zamioudis, C., Berendsen, R. L., Weller, D. M., Van Wees, S. C. M., and Bakker, P. A. H. M. (2014). Induced systemic resistance by beneficial microbes. Annu. Rev. Phytopathol. 52, 347-375. doi: 10.1146/ annurev-phyto-082712-102340

Pirgozliev, S. R., Edwards, S. G., Hare, M. C., and Jenkinson, P. (2003). Strategies for the control of fusarium head blight in cereals. Eur. J. Plant Pathol. 109, 731-742. doi: 10.1023/A:1026034509247

Pirgozliev, S. R., Ray, R. V., Edwards, S. G., Hare, M. C., and Jenkinson, P. (2012). Studies on the interactions between fungicides, Alternaria tenuissima
Cladosporium herbarum and Microdochium spp., on Fusarium head blight (FHB) development and deoxynivalenol (DON) concentration in grain caused by Fusarium culmorum. Cereal Res. Commun. 40, 509-517. doi: 10.1556/CRC. 2012.0010

Rastogi, G., Coaker, G. L., and Leveau, J. H. J. (2013). New insights into the structure and function of phyllosphere microbiota through high-throughput molecular approaches. FEMS Microbiol. Lett. 348, 1-10. doi: 10.1111/15746968.12225

Ritpitakphong, U., Falquet, L., Vimoltust, A., Berger, A., Métraux, J.-P., and L'Haridon, F. (2016). The microbiome of the leaf surface of Arabidopsis protects against a fungal pathogen. New Phytol. 210, 1033-1043. doi: 10.1111/nph.13808

Rodríguez, M. A., Cabrera, G., Gozzo, F. C., Eberlin, M. N., and Godeas, A (2011). Clonostachys rosea BAFC3874 as a Sclerotinia sclerotiorum antagonist: mechanisms involved and potential as a biocontrol agent. J. Appl. Microbiol. 110, 1177-1186. doi: 10.1111/j.1365-2672.2011.04970.x

Rojas, E. C., Jensen, B., Jørgensen, H. J. L., Latz, M. A. C., Esteban, P., Ding, Y., et al. (2020). Selection of fungal endophytes with biocontrol potential against Fusarium head blight in wheat. Biol. Control 144:104222. doi: 10.1016/j. biocontrol.2020.104222

Sapkota, R., Jørgensen, L. N., and Nicolaisen, M. (2017). Spatiotemporal variation and networks in the mycobiome of the wheat canopy. Front. Plant Sci. 8:1357. doi: $10.3389 /$ fpls.2017.01357

Sapkota, R., Knorr, K., Jørgensen, L. N., O’Hanlon, K. A., and Nicolaisen, M. (2015). Host genotype is an important determinant of the cereal phyllosphere mycobiome. New Phytol. 207, 1134-1144. doi: 10.1111/nph.13418

Schiro, G., Verch, G., Grimm, V., and Müller, M. E. H. (2018). Alternaria and Fusarium fungi: differences in distribution and spore deposition in a topographically heterogeneous wheat field. J. Fungi 4:63. doi: 10.3390/ jof4020063

Schisler, D. A., Khan, N. I., Boehm, M. J., Lipps, P. E., Slininger, P. J., and Zhang, S. (2006). Selection and evaluation of the potential of choline-metabolizing microbial strains to reduce Fusarium head blight. Biol. Control 39, 497-506. doi: 10.1016/j.biocontrol.2006.08.007

Schlatter, D., Kinkel, L., Thomashow, L., Weller, D., and Paulitz, T. (2017). Disease suppressive soils: new insights from the soil microbiome. Phytopathology 107, 1284-1297. doi: 10.1094/PHYTO-03-17-0111-RVW

Schöneberg, A., Musa, T., Voegele, R. T., and Vogelgsang, S. (2015). The potential of antagonistic fungi for control of Fusarium graminearum and Fusarium crookwellense varies depending on the experimental approach. J. Appl. Microbiol. 118, 1165-1179. doi: 10.1111/jam.12775

Schöneberg, T., Jenny, E., Wettstein, F. E., Bucheli, T. D., Mascher, F., Bertossa, M., et al. (2018). Occurrence of Fusarium species and mycotoxins in Swiss oatsImpact of cropping factors. Eur. J. Agron. 92, 123-132. doi: 10.1016/j.eja.2017. 09.004

Schöneberg, T., Martin, C., Wettstein, F. E., Bucheli, T. D., Mascher, F., Bertossa, M., et al. (2016). Fusarium and mycotoxin spectra in Swiss barley are affected by various cropping techniques. Food Addit. Contam. Part A 33, 1608-1619. doi: 10.1080/19440049.2016.1219071

Seybold, H., Demetrowitsch, T. J., Hassani, M. A., Szymczak, S., Reim, E., Haueisen, J., et al. (2020). A fungal pathogen induces systemic susceptibility and systemic shifts in wheat metabolome and microbiome composition. Nat. Commun. 11:1910. doi: 10.1038/s41467-020-15633-x

Shikur Gebremariam, E., Sharma-Poudyal, D., Paulitz, T. C., Erginbas-Orakci, G., Karakaya, A., and Dababat, A. A. (2018). Identity and pathogenicity of Fusarium species associated with crown rot on wheat (Triticum spp.) in Turkey. Eur. J. Plant Pathol. 150, 387-399. doi: 10.1007/s10658-017-1285-7

Sieber, T. N., and Grünig, C. R. (2006). "Biodiversity of fungal root-endophyte communities and populations," in Particular of the Dark Septate Endophyte Phialocephala fortinii s. l.," in Microbial Root Endophytes, eds B. J. E. Schulz, C. J. C. Boyle, and T. N. Sieber (Berlin: Springer Berlin Heidelberg), 107-132. doi: 10.1007/3-540-33526-9_7

Simpson, D. R., Weston, G. E., Turner, J. A., Jennings, P., and Nicholson, P. (2001). Differential control of head blight pathogens of wheat by fungicides and consequences for mycotoxin contamination of grain. Eur. J. Plant Pathol. 107, 421-431. doi: 10.1023/A:1011225817707

Singer, E., Bushnell, B., Coleman-Derr, D., Bowman, B., Bowers, R. M., Levy, A., et al. (2016). High-resolution phylogenetic microbial community profiling. ISME J. 10, 2020-2032. doi: 10.1038/ismej.2015.249 
Siou, D., Gélisse, S., Laval, V., Elbelt, S., Repinçay, C., Bourdat-Deschamps, M., et al. (2015). Interactions between head blight pathogens: consequences for disease development and toxin production in wheat Spikes. Appl Env. Microbiol. 81, 957-965. doi: 10.1128/AEM.02879- 14

Siou, D., Gélisse, S., Laval, V., Repinçay, C., Canalès, R., Suffert, F., et al. (2014). Effect of wheat spike infection timing on Fusarium head blight development and mycotoxin accumulation. Plant Pathol. 63, 390-399. doi: 10.1111/ppa. 12106

Starkey, D. E., Ward, T. J., Aoki, T., Gale, L. R., Kistler, H. C., Geiser, D. M., et al. (2007). Global molecular surveillance reveals novel Fusarium head blight species and trichothecene toxin diversity. Fungal Genet. Biol. 44, 1191-1204. doi: 10.1016/j.fgb.2007.03.001

Summerell, B. A., Laurence, M. H., Liew, E. C. Y., and Leslie, J. F. (2010). Biogeography and phylogeography of Fusarium: a review. Fungal Divers. 44, 3-13. doi: 10.1007/s13225-010-0060-2

Sundh, I., and Goettel, M. S. (2013). Regulating biocontrol agents: a historical perspective and a critical examination comparing microbial and macrobial agents. BioControl 58, 575-593. doi: 10.1007/s10526-012-9498-3

Sundh, I., and Eilenberg, J. (2020). Why has the authorization of microbial biological control agents been slower in the EU than in comparable jurisdictions? Pest Manag. Sci. doi: 10.1002/ps.6177 [Epub ahead of print].

Sundheim, L., Brodal, G., Hofgaard, I., and Rafoss, T. (2013). Temporal variation of mycotoxin producing fungi in norwegian cereals. Microorganisms 1, 188-198. doi: 10.3390/microorganisms 1010188

Tan, J., Ameye, M., Landschoot, S., Zutter, N. D., Saeger, S. D., Boevre, M. D., et al. (2020). At the scene of the crime: new insights into the role of weakly pathogenic members of the Fusarium head blight disease complex. Mol. Plant Pathol. 21, 1559-1572. doi: 10.1111/mpp.12996

Tedersoo, L., Tooming-Klunderud, A., and Anslan, S. (2018). PacBio metabarcoding of Fungi and other eukaryotes: errors, biases and perspectives. New Phytol 217, 1370-1385. doi: 10.1111/nph.14776

Tekle, S., Dill-Macky, R., Skinnes, H., Tronsmo, A. M., and Bjørnstad, Å (2012). Infection process of Fusarium graminearum in oats (Avena sativa L.). Eur. J. Plant Pathol. 132, 431-442. doi: 10.1007/s10658-011-9888-x

Thrane, U., Adler, A., Clasen, P.-E., Galvano, F., Langseth, W., Lew, H., et al. (2004). Diversity in metabolite production by Fusarium langsethiae, Fusarium poae, and Fusarium sporotrichioides. Int. J. Food Microbiol. 95, 257-266. doi: 10.1016/j.ijfoodmicro.2003.12.005

Tillmann, M., von Tiedemann, A., and Winter, M. (2017). Crop rotation effects on incidence and diversity of Fusarium species colonizing stem bases and grains of winter wheat. J. Plant Dis. Prot. 124, 121-130. doi: 10.1007/s41348-0160064-6

Trail, F., Gaffoor, I., and Vogel, S. (2005). Ejection mechanics and trajectory of the ascospores of Gibberella zeae (anamorph Fuarium graminearum). Fungal Genet. Biol. 42, 528-533. doi: 10.1016/j.fgb.2005.03.008

Valente, J., Gerin, F., Gouis, J. L., Moënne-Loccoz, Y., and Prigent-Combaret, C. (2020). Ancient wheat varieties have a higher ability to interact with plant growth-promoting rhizobacteria. Plant Cell Environ. 43, 246-260. doi: 10.1111/ pce. 13652

Valverde-Bogantes, E., Bianchini, A., Herr, J. R., Rose, D. J., Wegulo, S. N., and Hallen-Adams, H. E. (2019). Recent population changes of Fusarium head blight pathogens: drivers and implications. Can. J. Plant Pathol. 0, 1-15. doi: 10.1080/07060661.2019.1680442

van Dijk, E. L., Jaszczyszyn, Y., Naquin, D., and Thermes, C. (2018). The third revolution in sequencing technology. Trends Genet. 34, 666-681. doi: 10.1016/ j.tig.2018.05.008

van Loon, C. (2007). Plant responses to plant growth-promoting rhizobacteria. Eur. J. Plant Pathol. 119, 243-254. doi: 10.1007/s10658-007-9165-1

Vandenkoornhuyse, P., Quaiser, A., Duhamel, M., Le Van, A., and Dufresne, A. (2015). The importance of the microbiome of the plant holobiont. New Phytol. 206, 1196-1206. doi: 10.1111/nph.13312

Vaughan, M. M., Ward, T. J., McCormick, S. P., Orwig, N., Hay, W. T., Proctor, R., et al. (2020). Intrapopulation antagonism can reduce the growth and aggressiveness of the wheat head blight pathogen Fusarium graminearum. Phytopathology 110, 916-926. doi: 10.1094/PHYTO-09-19-0341-R

Venkatesh, N., and Keller, N. P. (2019). Mycotoxins in conversation with bacteria and fungi. Front. Microbiol. 10:403. doi: 10.3389/fmicb.2019.00403
Vogelgsang, S., Musa, T., Bänziger, I., Kägi, A., Bucheli, T., Wettstein, F., et al. (2017). Fusarium mycotoxins in swiss wheat: a Survey of Growers' Samples between 2007 and 2014 shows strong year and minor geographic effects. Toxins 9:246. doi: 10.3390/toxins9080246

Vogelgsang, S., Sulyok, M., Hecker, A., Jenny, E., Krska, R., Schuhmacher, R., et al. (2008). Toxigenicity and pathogenicity of Fusarium poae and Fusarium avenaceum on wheat. Eur. J. Plant Pathol. 122, 265-276. doi: 10.1007/s10658008-9279-0

Vorholt, J. A. (2012). Microbial life in the phyllosphere. Nat. Rev. Microbiol. 10, 828-840. doi: 10.1038/nrmicro2910

Vorholt, J. A., Vogel, C., Carlström, C. I., and Müller, D. B. (2017). establishing causality: opportunities of synthetic communities for plant microbiome research. Cell Host Microbe 22, 142-155. doi: 10.1016/j.chom.2017.07.004

Waalwijk, C., van der Heide, R., de Vries, I., van der Lee, T., Schoen, C., Costrelde Corainville, G., et al. (2004). Quantitative detection of Fusarium species in wheat using TaqMan. Eur. J. Plant Pathol. 110, 481-494. doi: 10.1023/B: EJPP.0000032387.52385.13

Walder, F., Schlaeppi, K., Wittwer, R., Held, A. Y., Vogelgsang, S., Heijden, V. D., et al. (2017). Community profiling of Fusarium in combination with other plant-associated fungi in different crop species using SMRT sequencing. Front. Plant Sci. 8:2019. doi: 10.3389/fpls.2017.02019

Walkowiak, S., Bonner, C. T., Wang, L., Blackwell, B., Rowland, O., and Subramaniam, R. (2015). Intraspecies interaction of Fusarium graminearum contributes to reduced toxin production and virulence. Mol. Plant. Microbe Interact. 28, 1256-1267. doi: 10.1094/MPMI-06-15-0120-R

Ward, T. J., Clear, R. M., Rooney, A. P., O’Donnell, K., Gaba, D., Patrick, S., et al. (2008). An adaptive evolutionary shift in Fusarium head blight pathogen populations is driving the rapid spread of more toxigenic Fusarium graminearum in North America. Fungal Genet. Biol. 45, 473-484. doi: 10.1016/ j.fgb.2007.10.003

Wegulo, S. N., Baenziger, P. S., Hernandez Nopsa, J., Bockus, W. W., and HallenAdams, H. (2015). Management of Fusarium head blight of wheat and barley. Crop Prot. 73, 100-107. doi: 10.1016/j.cropro.2015.02.025

Wei, Z., and Jousset, A. (2017). Plant breeding goes microbial. Trends Plant Sci. 22, 555-558. doi: 10.1016/j.tplants.2017.05.009

Wolfarth, F., Schrader, S., Oldenburg, E., Weinert, J., and Brunotte, J. (2011). Earthworms promote the reduction of Fusarium biomass and deoxynivalenol content in wheat straw under field conditions. Soil Biol. Biochem. 43, 18581865. doi: 10.1016/j.soilbio.2011.05.002

Xu, X., Nicholson, P., and Ritieni, A. (2007). Effects of fungal interactions among Fusarium head blight pathogens on disease development and mycotoxin accumulation. Int. J. Food Microbiol. 119, 67-71. doi: 10.1016/j.ijfoodmicro. 2007.07.027

Xu, X.-M., Monger, W., Ritieni, A., and Nicholson, P. (2007). Effect of temperature and duration of wetness during initial infection periods on disease development, fungal biomass and mycotoxin concentrations on wheat inoculated with single, or combinations of. Fusarium species. Plant Pathol. 56, 943-956. doi: 10.1111/j.1365-3059.2007.01650.x

Xu, X.-M., Nicholson, P., Thomsett, M. A., Simpson, D., Cooke, B. M., Doohan, F. M., et al. (2008). Relationship between the fungal complex causing Fusarium head blight of wheat and environmental conditions. Phytopathology 98, 69-78. doi: 10.1094/PHYTO-98-1-0069

Xu, X.-M., Parry, D. W., Nicholson, P., Thomsett, M. A., Simpson, D., Edwards, S. G., et al. (2005). Predominance and association of pathogenic fungi causing Fusarium ear blight in wheat in four European countries. Eur. J. Plant Pathol. 112, 143-154. doi: 10.1007/s10658-005-2446-7

Yli-Mattila, T. (2010). Ecology and evolution of toxigenic Fusarium species in cereals in Northern Europe and Asia. J. Plant Pathol. 92, 7-18.

Yli-Mattila, T., Paavanen-Huhtala, S., Jestoi, M., Parikka, P., Hietaniemi, V., Gagkaeva, T., et al. (2008). Real-time PCR detection and quantification of Fusarium poae, F. graminearum, F. sporotrichioides and F. langsethiae in cereal grains in Finland and Russia. Arch. Phytopathol. Plant Prot. 41, 243-260. doi: 10.1080/03235400600680659

Yoshida, M., Kawada, N., and Nakajima, T. (2007). Effect of infection timing on Fusarium head blight and mycotoxin accumulation in open- and closedflowering Barley. Phytopathology 97, 1054-1062. doi: 10.1094/PHYTO-97-91054 
Zahn, G., and Amend, A. S. (2017). Foliar microbiome transplants confer disease resistance in a critically-endangered plant. PeerJ 5:e4020. doi: 10.7717/peerj. 4020

Zetzsche, H., Friedt, W., and Ordon, F. (2020). Breeding progress for pathogen resistance is a second major driver for yield increase in German winter wheat at contrasting N levels. Sci. Rep. 10:20374. doi: 10.1038/s41598-020-77 200-0

Zhang, Z., Nie, D., Fan, K., Yang, J., Guo, W., Meng, J., et al. (2020). A systematic review of plant-conjugated masked mycotoxins: occurrence, toxicology, and metabolism. Crit. Rev. Food Sci. Nutr. 60, 1523-1537. doi: 10.1080/10408398. 2019.1578944

Zhao, Y., Selvaraj, J. N., Xing, F., Zhou, L., Wang, Y., Song, H., et al. (2014). Antagonistic Action of Bacillus subtilis Strain SG6 on Fusarium graminearum. PLoS One 9:e92486. doi: 10.1371/journal.pone.0092486
Zinkernagel, V., Adolf, B., and Habermeyer, J. (1997). The spread of Fusarium spp. from the above ground level to the ears of wheat. Cereal Res. Commun. 25, $677-679$.

Conflict of Interest: The authors declare that the research was conducted in the absence of any commercial or financial relationships that could be construed as a potential conflict of interest.

Copyright (c) 2021 Karlsson, Persson and Friberg. This is an open-access article distributed under the terms of the Creative Commons Attribution License (CC BY). The use, distribution or reproduction in other forums is permitted, provided the original author(s) and the copyright owner(s) are credited and that the original publication in this journal is cited, in accordance with accepted academic practice. No use, distribution or reproduction is permitted which does not comply with these terms. 